\title{
A Neutral pH Aqueous Organic-Organometallic Redox Flow Battery with Extremely High Capacity Retention
}

\section{Citation}

Beh, Eugene S., Diana De Porcellinis, Rebecca L. Gracia, Kay T. Xia, Roy G. Gordon, and Michael J. Aziz. 2017. "A Neutral pH Aqueous Organic-Organometallic Redox Flow Battery with Extremely High Capacity Retention." ACS Energy Letters 2 (3) (February 13): 639-644. doi:10.1021/acsenergylett.7b00019.

\section{Published Version}

10.1021/acsenergylett.7b00019

\section{Permanent link}

http://nrs.harvard.edu/urn-3:HUL.InstRepos:32749938

\section{Terms of Use}

This article was downloaded from Harvard University's DASH repository, and is made available under the terms and conditions applicable to Open Access Policy Articles, as set forth at http:// nrs.harvard.edu/urn-3:HUL.InstRepos:dash.current.terms-of-use\#OAP

\section{Share Your Story}

The Harvard community has made this article openly available.

Please share how this access benefits you. Submit a story.

Accessibility 


\section{A Neutral pH Aqueous Organic/Organometallic}

\section{Redox Flow Battery with Extremely High Capacity}

\section{Retention}

Eugene S. Beh, ${ }^{\dagger, \dagger}$ Diana De Porcellinis, ${ }^{\dagger, \#}$ Rebecca L. Gracia, ${ }^{\prime \prime}$ Kay T. Xia, ${ }^{\|}$Roy G. Gordon, ${ }^{\dagger, t, *}$ and Michael J. Aziz ${ }^{\dagger} *$

${ }^{\dagger}$ John A. Paulson School of Engineering and Applied Sciences, Harvard University, Cambridge,

$$
\text { MA 02138, USA }
$$

*Department of Chemistry and Chemical Biology, Harvard University, Cambridge, MA 02138, USA

\#Department of Chemical Science and Technologies, University of Rome “Tor Vergata", Rome, Italy

"Harvard College, Cambridge, MA 02138, USA

*To whom correspondence should be addressed: gordon@chemistry.harvard.edu (Roy G. Gordon); maziz@harvard.edu (Michael J. Aziz). 


\section{ABSTRACT}

We demonstrate an aqueous organic and organometallic redox flow battery utilizing reactants composed only of earth-abundant elements and operating at neutral $\mathrm{pH}$. The positive electrolyte contains bis((3-trimethylammonio)propyl)ferrocene dichloride and the negative electrolyte contains bis(3-trimethylammonio)propyl viologen tetrachloride, separated by an anionconducting membrane passing chloride ions. Bis(trimethylammoniopropyl) functionalization leads to $\sim 2 \mathrm{M}$ solubility for both reactants, suppresses higher order chemical decomposition pathways, and reduces reactant crossover rates through the membrane. Unprecedented cycling stability was achieved with capacity retention of $99.9943 \% /$ cycle and $99.90 \% /$ day at a $1.3 \mathrm{M}$ reactant concentration, increasing to $99.9989 \%$ /cycle and $99.967 \%$ /day at $0.75-1.00 \mathrm{M}$; these represent the highest capacity retention rates reported to date $v s$. time and $v s$. cycle number. We point out opportunities for future performance improvement, including chemical modification of a ferrocene center and reducing the membrane resistance without unacceptable increases in reactant crossover. This approach may provide the decadal lifetimes that enable organic/organometallic redox flow batteries to be cost-effective for grid-scale electricity storage, thereby enabling massive penetration of intermittent renewable electricity.
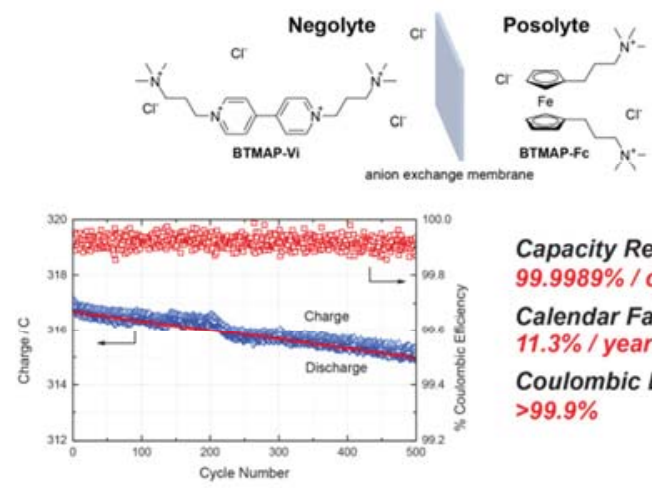
The rapidly falling cost of solar and wind energy generation has paved the way for large-scale adoption; however, storage is of critical importance due to the inherent intermittency of these renewable sources. ${ }^{1-3}$ Solid-electrode batteries such as Li-ion are common, but cannot be discharged cost-effectively for the several hours' duration required for effectively regulating wind and photovoltaic electricity production. ${ }^{1-2}$ By storing the electro-active chemical species separately from the power generation stack itself, and pumping the reactants past the electrodes when required, redox flow batteries (RFBs) allow the energy capacity of the entire system to be scaled independently of its maximum power output, thereby offering the promise of costeffective long-duration discharge. ${ }^{3-4}$

The most popular reactant for RFBs is vanadium, but low earth abundance, high cost, and volatile price limit its widespread commercial adoption. ${ }^{5}$ Many other inorganic reactant combinations have been studied, but none have proven more competitive, due to problems such as reactant cost, corrosivity, toxicity, slow kinetics, solubility, energy efficiency, and undesired side reactions. ${ }^{6-7}$

By employing solutions of redox-active organic ${ }^{8-13}$ or organometallic ${ }^{14-19}$ reactants incorporating only earth-abundant metals, the reactant cost can potentially be lowered substantially while eliminating any concerns about the availability of the reactants when applied to the truly large scales required for grid storage.

In addition to RFBs operating under highly $\operatorname{acidic}^{8}$ or alkaline ${ }^{15-16}$ conditions, several chemistries have been reported that operate at neutral $\mathrm{pH}$, where the low corrosivity is advantageous. ${ }^{11-13,19}$ (See Table $\mathbf{S 1}$ for a summary of neutral $\mathrm{pH}$ aqueous organic RFB chemistries.) However, the reported capacity retentions have still been too low for decadal operation. Because chemical stability and electrochemical stability are distinct and independent 
metrics, the capacity retention per cycle reported from rapid cycling experiments does not address calendar-life limitations, which are particularly relevant for molecular reactants. In this paper, we report a RFB with the highest capacity retention rate to date $v s$. time and $v s$. cycle number. The RFB is operated in water at neutral $\mathrm{pH}$, using organic and organometallic reactants that have very high solubilities $(\sim 2 \mathrm{M})$ in water and do not require any added supporting electrolyte.

The neutral $\mathrm{pH}$ organic RFBs reported to date utilize methyl viologen (MV) monomers or polymers as the negolyte (negative electrolyte) and typically a nitroxide radical such as $(2,2,6,6-$ tetramethylpiperidin-1-yl)oxyl (TEMPO) in monomeric or polymeric form as the positive electrolyte (posolyte), where chloride ions move across an anion-conducting membrane during operation. A very recent report has introduced water-soluble ferrocene derivatives $\mathbf{F c N C l}$ and $\mathbf{F c N}_{2} \mathbf{B r}_{2}$ (Table S1) in an alternative posolyte for $\mathrm{pH} 7$ RFBs. ${ }^{19}$ All three species (viologen, TEMPO, and ferrocene) are susceptible to decomposition via mechanisms that involve the collision of two of the same molecule in a second-order process. (See SI for details about the decomposition mechanisms.) This is of particular concern because high reactant concentrations are required in order to achieve high energy densities; indeed, whenever different reactant concentrations have been reported for the same reactant chemistries, lower capacity retention rates have always been observed at higher concentrations of molecular reactants (Table S1).

We therefore designed and synthesized bis(3-trimethylammonio)propyl viologen tetrachloride

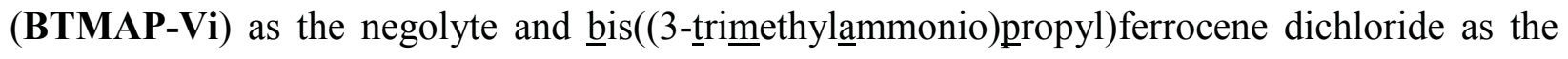
posolyte (BTMAP-Fc; See SI). The existence of four positive charges instead of two on the cationic constituent $\mathrm{MV}^{2+}$ (for the reduced forms, three vs. one for the cation radical $\mathrm{MV}^{\circ+}$ ) was hypothesized to retard greatly the bimolecular decomposition of BTMAP-Vi by a massive 
increase in the Coulombic repulsion between two molecules compared to $\mathrm{MV}^{2+} / \mathrm{MV}^{\circ+}$. A similar effect was hypothesized also to increase the chemical stability of BTMAP-Fc compared to FcNCl. Both BTMAP-Vi and BTMAP-Fc are composed of only earth-abundant elements.

In addition to the improved stability of both compounds compared to MV, TEMPO, and FcNCl, the two positively charged quaternary ammonium groups impart extremely high water solubility to the molecules. For instance, ferrocene is completely insoluble in water but BTMAP-Fc has a solubility of $1.9 \mathrm{M}$ in water at $20^{\circ} \mathrm{C}$; BTMAP-Vi has a similar solubility of 2.0 M in water. Moreover, the highly positively charged reactants are expected to also benefit from reduced permeability across anion exchange membranes through enhanced charge and size exclusion. ${ }^{20}$ The permeabilities of BTMAP-Vi and BTMAP-Fc across a Selemion DSV anion exchange membrane were measured to be $6.7 \times 10^{-10} \mathrm{~cm}^{2} \mathrm{~s}^{-1}$ and $6.2 \times 10^{-10} \mathrm{~cm}^{2} \mathrm{~s}^{-1}$ respectively. (See SI) These permeabilities are 5 times lower than MV, which was measured at $3.4 \times 10^{-9} \mathrm{~cm}^{2} \mathrm{~s}^{-1}$. From these values, it would take 10.8 and 11.6 years, respectively, for the crossover of BTMAP-Vi and BTMAP-Fc to lead to a 50\% loss in cell capacity.

Rotating disk electrode (RDE) voltammetry measurements (see SI) on both reactants gave a reduction rate constant of $2.2 \times 10^{-2} \mathrm{~cm} \mathrm{~s}^{-1}$ for BTMAP-Vi and an oxidation rate constant of 1.4 $\times 10^{-2} \mathrm{~cm} \mathrm{~s}^{-1}$ for BTMAP-Fc, which are much faster than common inorganic species, ${ }^{5}$ and are also faster than most other organic or organometallic reactants ${ }^{8-9,11,15-16}$ that have been used in RFBs. The diffusion coefficients for the two reactants were $3.3 \times 10^{-6} \mathrm{~cm}^{2} \mathrm{~s}^{-1}$ and $3.1 \times 10^{-6} \mathrm{~cm}^{2}$ $\mathrm{s}^{-1}$ respectively.

Figure 1 shows cyclic voltammograms for BTMAP-Vi and BTMAP-Fc. (See SI) When used in the negolyte and posolyte, respectively, in a RFB, the expected cell potential is $0.748 \mathrm{~V}$. With the high solubilities of both electrolytes in water, the theoretical volumetric capacity (including 
both electrolytes in the denominator) is $26 \mathrm{Ah} \mathrm{L}^{-1}$ and the theoretical energy density is $20 \mathrm{Wh} \mathrm{L}^{-1}$.
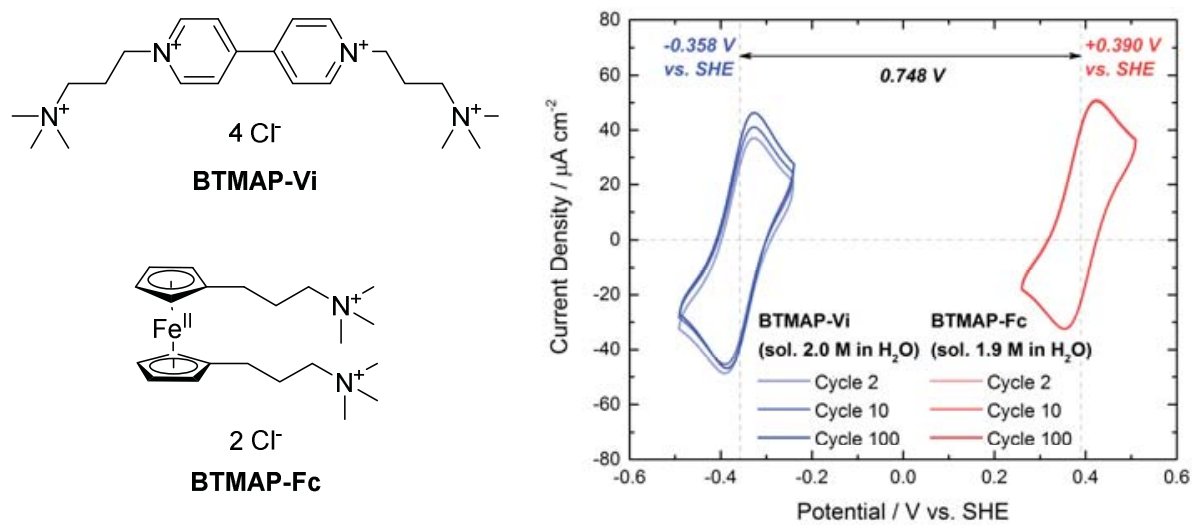

Figure 1. Left: Chemical structures of BTMAP-Vi and BTMAP-Fc. Right: Cyclic voltammograms of BTMAP-Vi (blue trace) and BTMAP-Fc (red trace). The water solubilities and reduction potentials of both molecules vs. the standard hydrogen electrode (SHE) are indicated. Note that as BTMAP-Vi is cycled, the solution near the working electrode is gradually depleted of dissolved oxygen. Conditions: $1.0 \mathrm{mM}$ in $0.5 \mathrm{M} \mathrm{NaCl}, 10 \mathrm{mV} \mathrm{s}^{-1}$ sweep rate. The $2^{\text {nd }}$, $10^{\text {th }}$, and $100^{\text {th }}$ cycles are superimposed.

A cell (see SI for details) was assembled using 1.3 M BTMAP-Vi in water $(6.00 \mathrm{~mL})$ as the negolyte and 1.3 M BTMAP-Fc in water $(6.00 \mathrm{~mL})$ as the posolyte, separated by an anionconducting membrane (Selemion DSV, $110 \mu \mathrm{m} \times 5 \mathrm{~cm}^{2}$ ). In order to prevent atmospheric oxygen from reacting with either electrolyte and promoting decomposition by raising the solution $\mathrm{pH}$, the entire cell was operated inside an argon-filled glove box. Both electrolyte solutions were also stirred overnight under an argon atmosphere immediately prior to use.

The resulting neutral $\mathrm{pH}$ aqueous $\mathrm{RFB}$ showed an open-circuit voltage $(\mathrm{OCV})$ that increased nearly linearly from $0.61 \mathrm{~V}$ at $10 \%$ state of charge (SOC) to $0.79 \mathrm{~V}$ at $90 \%$ SOC. (Figure 2) Polarization studies conducted at room temperature $\left(20^{\circ} \mathrm{C}\right)$ showed a peak galvanic power 
density of $60 \mathrm{~mW} \mathrm{~cm}{ }^{-2}$ at a current density of $150 \mathrm{~mA} \mathrm{~cm}^{-2}$. The relatively low peak power and current densities were due in large part to the resistivity of the membrane $\left(\sim 2.2 \Omega \mathrm{cm}^{2}\right.$, determined by high-frequency electrochemical impedance spectroscopy (EIS) in the full cell; see SI), which was responsible for approximately $75 \%-90 \%$ of the area-specific resistance (ASR) of the entire cell $\left(\sim 2.5 \Omega \mathrm{cm}^{2}\right.$, DC polarization). Because of the high Coulombic efficiency $\left(99.8 \%-99.9 \%\right.$ for current densities of $\left.25-125 \mathrm{~mA} \mathrm{~cm}^{-2}\right)$, the voltage efficiency dominated the overall round-trip energy efficiency.
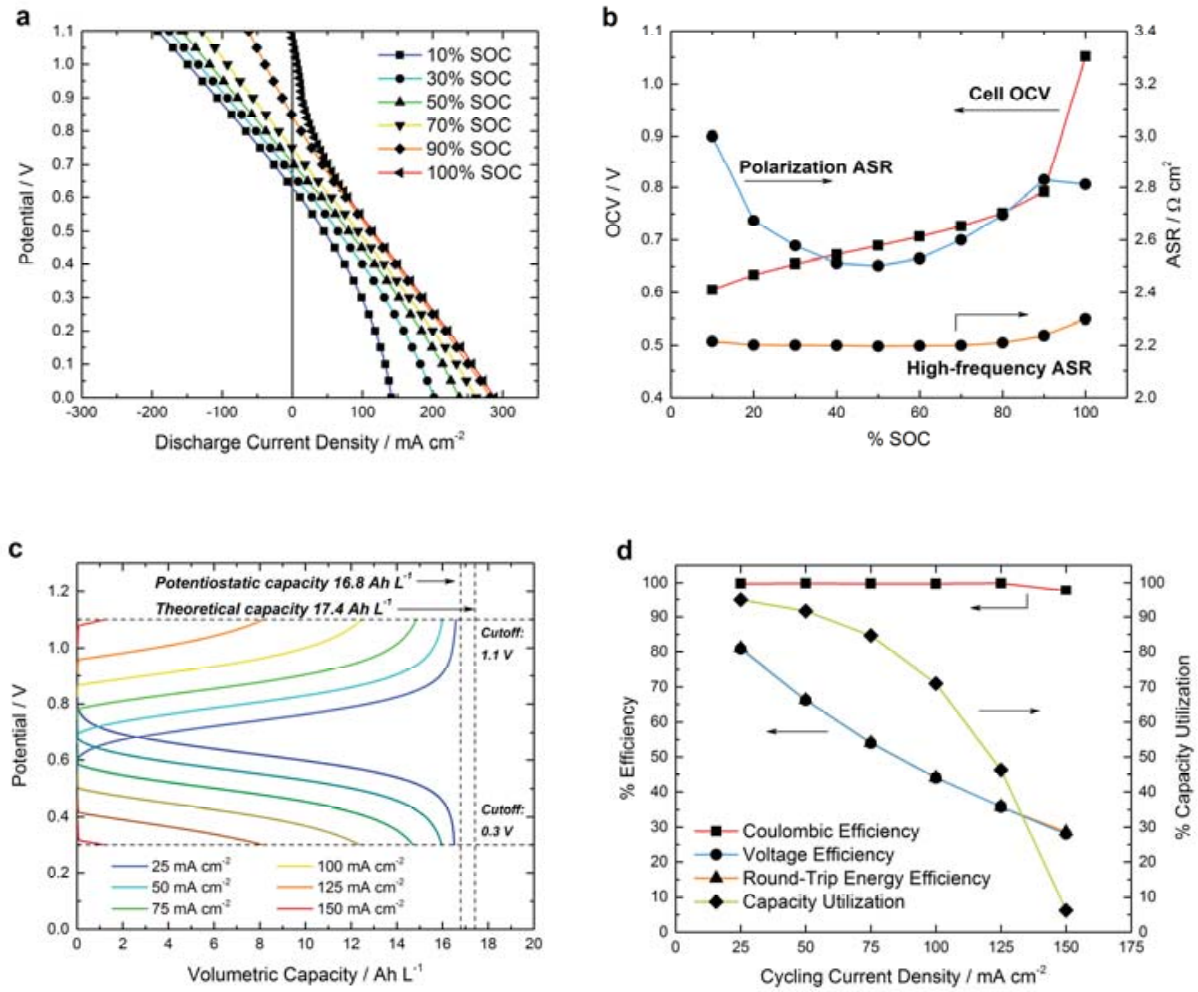

Figure 2. (a) Cell voltage $v$ s. discharge current density at $20^{\circ} \mathrm{C}$, at $10 \%, 30 \%, 50 \%, 70 \%, 90 \%$, and $\sim 100 \%$ SOC. Electrolytes comprise $6.00 \mathrm{~mL}$ of $1.3 \mathrm{M}$ BTMAP-Vi (negolyte) and $6.00 \mathrm{~mL}$ of 1.3 M BTMAP-Fc (posolyte). (b) Measured cell OCV, high-frequency ASR, and polarization ASR vs. SOC. (c) Representative galvanostatic charge and discharge curves from $25 \mathrm{~mA} \mathrm{~cm}^{-2}$ to $150 \mathrm{~mA} \mathrm{~cm}^{-2}$, in increments of $25 \mathrm{~mA} \mathrm{~cm}^{-2}$. The vertical dashed lines indicate the maximum 
volumetric capacity realized with potentiostatic charging and discharging at the indicated voltage cutoffs ("potentiostatic capacity"), as well as the theoretical volumetric capacity. (d) Coulombic efficiency, voltage efficiency, and round-trip energy efficiency (red/blue/orange traces, left axis), as well as capacity utilization (green trace, right axis) as a percentage of theoretical capacity for cell operation at different current densities.

An extended charge-discharge study was performed to investigate the stabilities of BTMAPVi and BTMAP-Fc. (Figure 3) In order to minimize the effect of oxygen on capacity retention (see SI), the cell was charged to $\sim 100 \% \mathrm{SOC}$ and $1.00 \mathrm{~mL}$ of posolyte was withdrawn through a syringe. (See SI for the cycling performance of a cell operating at a 1:1 reactant molar ratio in oxygen-containing and oxygen-depleted environments, and for a comparison with $\mathbf{M V}$ as the negolyte instead of BTMAP-Vi.) The cell was then cycled at a constant current of $50 \mathrm{~mA} \mathrm{~cm}^{-2}$, with a potential cutoff of $1.1 \mathrm{~V}$ while charging and $0.3 \mathrm{~V}$ while discharging. The average Coulombic efficiency during galvanostatic cycling was $>99.95 \%$. (Figure S8) Every $10^{\text {th }}$ cycle, the potential was maintained at the cutoff voltage after galvanostatic charging and discharging until the current dropped below $1 \mathrm{~mA} \mathrm{~cm}{ }^{-2}$. This allowed the entire capacity of the cell to be measured, independent of any changes to the membrane ASR.

The membrane ASR was measured using potentiostatic EIS at $0.3 \mathrm{~V}$ immediately following the potentiostatic discharge from each $10^{\text {th }}$ cycle (i.e. always at $\sim 0 \%$ SOC). The membrane ASR was found to increase very slowly over the course of two weeks while showing diurnal variations of $\sim 0.05 \Omega \mathrm{cm}^{2}$ depending on the ambient temperature. Changes to the membrane ASR manifested as ripples in the cell capacity with a period of 1 day. Because the ASR slowly increased with time, diminished capacity utilization resulted in a larger apparent decrease in cell capacity over time compared to cycling with a potential hold. Thus, cycling with a potential hold 
provides a more accurate measure of reactant stability in an operating cell than conventional galvanostatic cycling. In addition, because the potential holds ensure that the entire SOC range is accessed, the cell does not have to achieve a steady-state SOC range, which could otherwise obscure the actual capacity retention rate.
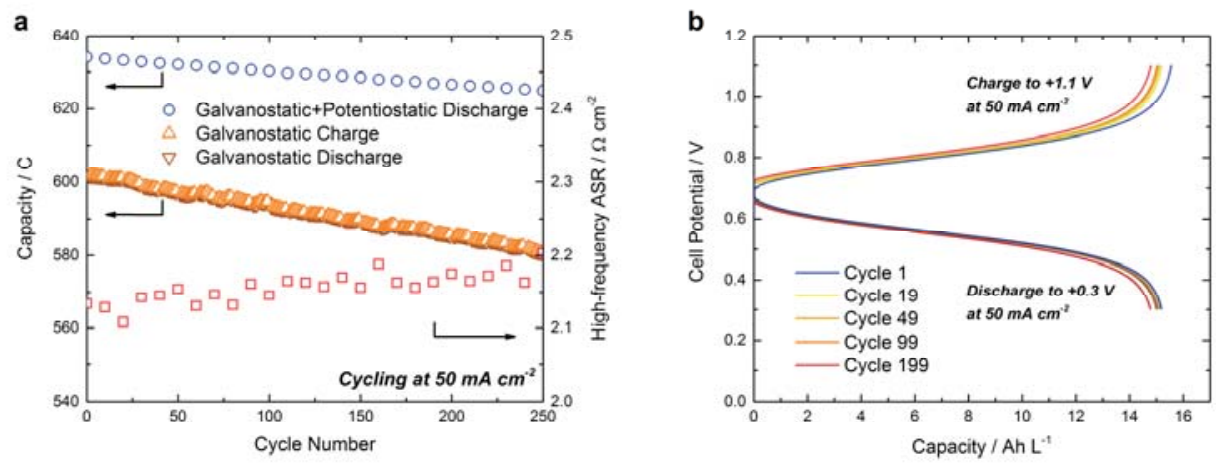

Figure 3. (a) Evolution of the capacity of the BTMAP-Vi/BTMAP-Fc RFB at a concentration of $1.3 \mathrm{M} / 1.3 \mathrm{M}$ during extended cell cycling at $50 \mathrm{~mA} \mathrm{~cm}^{-2}$ (orange and brown triangles, left axis). At every $10^{\text {th }}$ cycle, the potential was maintained at the end of each charge or discharge until the current fell below $1 \mathrm{~mA} \mathrm{~cm}{ }^{-2}$ (blue circles, left axis). The high-frequency ASR, which was measured immediately after every $10^{\text {th }}$ cycle, is also indicated (red squares, right axis). (b) Representative voltage $v s$. time traces of selected cycles. Cycles that were multiples of $(10 n-1)$ were chosen because every $10^{\text {th }}$ cycle was different (see above).

At a concentration of $1.3 \mathrm{M}$ for BTMAP-Vi and BTMAP-Fc, the cell capacity had fallen to $98.58 \%$ of its original value (633.981 C to $624.952 \mathrm{C}$ ) over 250 cycles (which spanned 14.0 days), representing a capacity retention of $99.9943 \%$ / cycle or $99.90 \%$ / day. The corresponding capacity fade rates are $0.0057 \% /$ cycle and $0.10 \% /$ day respectively. The former figure attributes all of the capacity fade to electrochemical cycling whereas the latter figure attributes it 
all to chemical decay; thus these figures represent upper limits if both mechanisms contribute significantly to capacity fade.

Even better capacity retention rates are achievable at lower, but still reasonable, reactant concentrations. Because operation in air led to a very fast drop in cell capacity (See SI), another cell was set up inside a nitrogen-filled glove bag with $7.50 \mathrm{~mL}$ of $0.75 \mathrm{M}$ BTMAP-Vi as the negolyte and $3.25 \mathrm{~mL}$ of $1.00 \mathrm{M}$ BTMAP-Fe as the posolyte, both at $100 \%$ SOC. (See SI) The glove bag environment contains more oxygen than does the glove box, but this is mitigated by the excess of reduced BTMAP-Vi that is present. This ratio of reactant concentrations was empirically chosen because it minimized water crossover from one reservoir to the other. Next, the cell was cycled for 500 cycles at $50 \mathrm{~mA} \mathrm{~cm}^{-2}$, this time with a voltage hold after every cycle (Figure 4). The 500 cycles required 16.6 days to complete. The average capacity retention over the 500 cycles was $99.9989 \%$ / cycle at an average Coulombic efficiency greater than $99.9 \%$, which reflects a capacity fade rate roughly $3-5$ times lower $(0.0011 \%$ / cycle; $0.033 \%$ / day $)$ at the same current density than for the cell described in Figure 3. The corresponding calendar fade rate is $11.3 \%$ / year, of which $\sim 6 \%$ / year comes from reactant crossover as calculated from the reactant permeabilities (see above). Compared to the $\mathbf{M V} / \mathbf{F c N C l}$ system, the capacity fade per cycle is reduced by a factor of $10(v s .0 .013 \%$ / cycle at $0.5 \mathrm{M})$ to $40(v s .0 .042 \%$ / cycle at $0.7 \mathrm{M})$ and the capacity fade per day by a factor of $20(v s .0 .58 \%$ / day at $0.5 \mathrm{M})$ to $40(v s .1 .3 \% /$ day at $0.7 \mathrm{M}$ ), despite still being at a higher reactant concentration. 

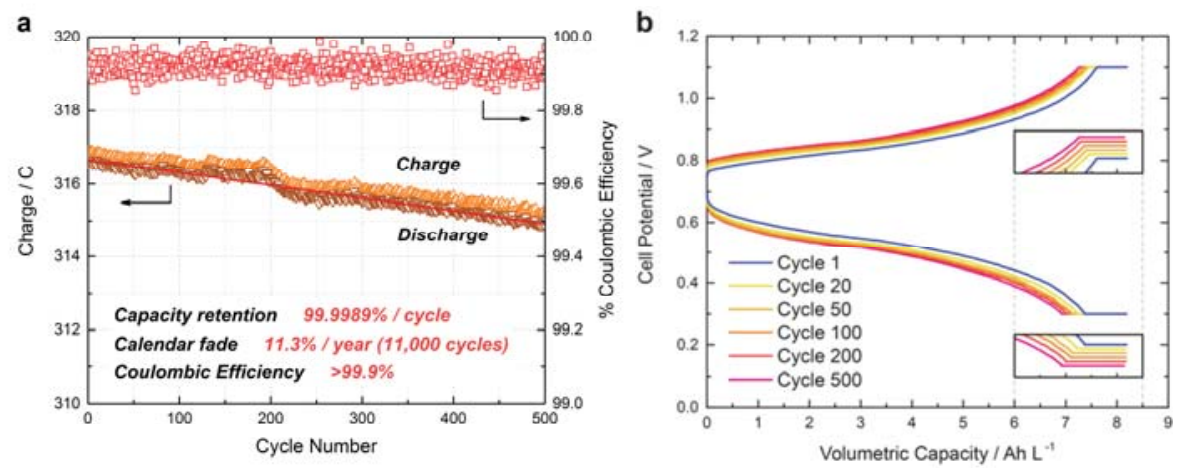

Figure 4. (a) Cycling of a BTMAP-Vi / BTMAP-Fc $\mathrm{pH} 7$ cell at $50 \mathrm{~mA} \mathrm{~cm}^{-2}$ in the presence of an excess of reduced BTMAP-Vi such that the posolyte is capacity-limiting. Bottom traces, left axis: Evolution of the cell charge (upward-pointing triangles) and discharge (downward-pointing triangles) capacity as functions of cycle number. Top trace, right axis: Coulombic efficiency of the cell for each charge-discharge cycle (red squares). The red line is the best fit line to the discharge capacity of the cell between cycles 1 and 500. (b) Representative voltage vs. time traces of selected cycles. Inset: Magnification of the potentiostatic regions of each chargedischarge cycle, showing the evolution of the potentiostatic capacity of the cell with cycle number. Inset traces are vertically offset from each other for clarity.

The calendar fade rate of a BTMAP-Vi / BTMAP-Fc cell was found to be independent of the cycling current density (Figure S6), implying that the predominant source of capacity fade is unlikely to be electrochemical decomposition, but rather chemical decomposition or reactant crossover. NMR analyses were performed to evaluate the extent to which chemical decomposition of the reactants at either charge state contributed to capacity loss. (See SI for details.) No trace of either reactant was detectable by NMR in the other reactant reservoir after 250 cycles (at high concentration) or 500 cycles (at lower concentration). Both reactants, in both their oxidized and reduced states, cycled or uncycled, were found by NMR to be stable in 
aqueous solution. Observed only with experiments in the glove bag but not the glove box, the dealkylation of BTMAP-Vi with hydroxide formed from the reaction of its reduced form with oxygen was identified as a decomposition pathway.

Our experiments imply that as long as oxygen is strictly excluded from the reactants, both BTMAP-Vi and BTMAP-Fc are electrochemically and chemically stable. From the examples in the literature, the percentage capacity fade is generally higher at higher concentrations of reactants, which suggests that a significant portion of the capacity fade is due to bimolecular reactions of the reactants with themselves. Presumably, these pathways are suppressed by the positive charges of BTMAP, which greatly increase the Coulombic repulsion between reactant molecules.

For practical applications, we expect that further improved temporal capacity retention over the already excellent result in Figure 4 will be possible by utilizing a cell design that is better sealed to atmospheric oxygen, or by simply scaling up the volume of the cell. A buffer solution may also be utilized to mitigate any rises in solution $\mathrm{pH}$, though the presence of large anions with low diffusivity from the buffer may potentially raise the cell ASR. Elsewhere, lowering the cell ASR by using more conductive membranes will help to compensate for the relatively low cell voltage, but this should not come at the expense of unacceptably high reactant crossover. Reactant permeabilities were measured in the absence of any external electrical polarization, so reactant crossover in a full cell could be of greater importance than our results suggest.

A complementary strategy is to replace BTMAP-Vi with a different molecule that has a lower reduction potential, or using a molecule with a higher reduction potential in place of BTMAP-Fc. This will have the effect of raising the cell voltage, the peak power density, and the energy efficiency of the cell. For instance, diquaternized derivatives of 2,2'-dipyridyl are known to have 
significantly lower (by $\sim 300 \mathrm{mV}$ ) reduction potentials than those of 4,4'-dipyridyl. ${ }^{21}$ For an alternative posolyte, we synthesized $N$-((3-trimethylammonio)propyl) ferrocenecarboxamide chloride (FcCONH-TMAP; see SI) and determined its reduction potential to be $+0.63 \mathrm{~V}$ vs. SHE (+1.04 V vs. RHE) at $\mathrm{pH}$ 7. This figure is $\sim 240 \mathrm{mV}$ higher than BTMAP-Fc, giving a theoretical cell potential of $0.99 \mathrm{~V}$ against BTMAP-Vi. Because an amide linkage is hydrolyzed in $\mathrm{pH} 7$ water at a rate with a corresponding half-life of several centuries, ${ }^{22}$ FcCONH-TMAP may be a suitably stable and synthetically accessible replacement for BTMAP-Fc in the future.

We have demonstrated an aqueous organic RFB utilizing reactants composed only of earthabundant elements and operating at $\mathrm{pH}$ 7. Functionalization of ferrocene and 4,4'-dipyridyl with BTMAP greatly improves solubility, leading to high realized and theoretical volumetric energy densities of $13 \mathrm{Wh} \mathrm{L}^{-1}$ and $20 \mathrm{Wh} \mathrm{L}^{-1}$, respectively at a cell voltage of $0.748 \mathrm{~V}$. Furthermore, BTMAP functionalization also suppresses reactant crossover through the membrane while ensuring high chemical and electrochemical stability.

The net result is a RFB that cycles stably with unprecedented capacity retention rates. Whether expressed in terms of cycle number or time $(99.9989 \%$ / cycle; calendar fade rate of $11.3 \%$ / year), this is a considerably higher capacity retention rate than for any other RFB chemistry that has been published to date, whether aqueous or nonaqueous, inorganic or organic/organometallic, polymeric or non-polymeric.

Our extrapolation of the performance of a battery with these properties indicates that if, once every day, it were charged completely over a five-hour period followed by a five-hour complete discharge, we would expect it to retain $50 \%$ of its energy storage capacity after 5,000 cycles, or about 14 years. The projected capacity retention is anticipated to be an underestimate because as the concentration of active material drops with time, the calendar fade rate will also decrease, i.e. 
the capacity fade rate has some greater than first-order component. Functionalization of reactants with bulky charged groups represents a promising strategy to developing next-generation aqueous organic RFBs with high capacity and high cycle life.

Supporting Information. Table of recent neutral pH aqueous RFB chemistries, additional cell cycling data, decomposition mechanisms of $\mathrm{pH} 7 \mathrm{RFB}$ reactants, and materials and methods.

Acknowledgments. This research was supported initially by ARPA-E award DE-AR0000348 and subsequently by DE-AC05-76RL01830 through PNNL subcontract 304500. The work was also supported by the Harvard School of Engineering and Applied Sciences and the Massachusetts Clean Energy Technology Center. We thank Prof. Marcel Schlaf, Marc-Antoni Goulet, David Kwabi, Zhengjin Yang, Michael Gerhardt, and Andrew Wong for useful discussions. 


\section{References}

(1) Dunn, B.; Kamath, H.; Tarascon, J. M. Electrical Energy Storage for the Grid: A Battery of Choices. Science 2011, 334, 928-935.

(2) Yang, Z.; Zhang, J.; Kintner-Meyer, M. C.; Lu, X.; Choi, D.; Lemmon, J. P.; Liu, J. Electrochemical Energy Storage for Green Grid. Chem. Rev. 2011, 111, 3577-3613.

(3) Nguyen, T.; Savinell, R. F. Flow Batteries. Electrochem. Soc. Interface 2010, 54-56.

(4) Skyllas-Kazacos, M.; Chakrabarti, M. H.; Hajimolana, S. A.; Mjalli, F. S.; Saleem, M. Progress in Flow Battery Research and Development. J. Electrochem. Soc. 2011, 158, R55.

(5) Weber, A. Z.; Mench, M. M.; Meyers, J. P.; Ross, P. N.; Gostick, J. T.; Liu, Q. Redox Flow Batteries: A Review. J. Appl. Electrochem. 2011, 41, 1137-1164.

(6) Soloveichik, G. L. Flow Batteries: Current Status and Trends. Chem. Rev. 2015, 115, 11533-11558.

(7) Winsberg, J.; Hagemann, T.; Janoschka, T.; Hager, M. D.; Schubert, U. S. Redox-Flow Batteries: From Metals to Organic Redox-Active Materials. Angew. Chem. Int. Ed. 2017, 56, 686-711.

(8) Huskinson, B.; Marshak, M. P.; Suh, C.; Er, S.; Gerhardt, M. R.; Galvin, C. J.; Chen, X.; Aspuru-Guzik, A.; Gordon, R. G.; Aziz, M. J. A Metal-Free Organic-Inorganic Aqueous Flow Battery. Nature 2014, 505, 195-198.

(9) Yang, B.; Hoober-Burkhardt, L.; Wang, F.; Surya Prakash, G. K.; Narayanan, S. R. An Inexpensive Aqueous Flow Battery for Large-Scale Electrical Energy Storage Based on WaterSoluble Organic Redox Couples. J. Electrochem. Soc. 2014, 161, A1371-A1380.

(10) Yang, B.; Hoober-Burkhardt, L.; Krishnamoorthy, S.; Murali, A.; Prakash, G. K. S.; Narayanan, S. R. High-Performance Aqueous Organic Flow Battery with Quinone-Based Redox Couples at Both Electrodes. J. Electrochem. Soc. 2016, 163, A1442-A1449.

(11) Liu, T.; Wei, X.; Nie, Z.; Sprenkle, V.; Wang, W. A Total Organic Aqueous Redox Flow Battery Employing a Low Cost and Sustainable Methyl Viologen Anolyte and 4-HO-TEMPO Catholyte. Adv. Energy Mater. 2016, 6, 1501449.

(12) Janoschka, T.; Martin, N.; Martin, U.; Friebe, C.; Morgenstern, S.; Hiller, H.; Hager, M. D.; Schubert, U. S. An Aqueous, Polymer-Based Redox-Flow Battery Using Non-Corrosive, Safe, and Low-Cost Materials. Nature 2015, 527, 78-81.

(13) Janoschka, T.; Martin, N.; Hager, M. D.; Schubert, U. S. An Aqueous Redox-Flow Battery with High Capacity and Power: The TEMPTMA/MV System. Angew. Chem. Int. Ed. 2016, 55, 14427-14430.

(14) Adams, G. B.; Hollandsworth, R. P.; Webber, B. D. Rechargeable Alkaline Zinc/Ferricyanide Battery: Final Report for the Period 29 September 1978-28 September 1979. Lockheed Palo Alto Research Laboratory, Lockheed Missiles \& Space Co.: Palo Alto, Calif., 1979.

(15) Lin, K.; Chen, Q.; Gerhardt, M. R.; Tong, L.; Kim, S. B.; Eisenach, L.; Valle, A. W.; Hardee, D.; Gordon, R. G.; Aziz, M. J. et al. Alkaline Quinone Flow Battery. Science 2015, 349, 1529-1532.

(16) Lin, K.; Gómez-Bombarelli, R.; Beh, E. S.; Tong, L.; Chen, Q.; Valle, A.; Aspuru-Guzik, A.; Aziz, M. J.; Gordon, R. G. A Redox-Flow Battery with an Alloxazine-Based Organic Electrolyte. Nat. Energy 2016, 1, 16102. 
(17) Goeltz, J.; Amadeo, D.; Esswein, A. J.; Jarvi, T. D.; King, E. R.; Reece, S. Y.; Tyagi, N. Aqueous Redox Flow Batteries Comprising Metal Ligand Coordination Compounds. U.S. Pat. App. 13/948,497, 2014.

(18) Esswein, A. J.; Goeltz, J.; Reece, S. Y.; Madden, T. D.; Amadeo, D.; Jarvi, T. D.; King, E. R. Aqueous Redox Flow Batteries Featuring Improved Cell Design Characteristics. U.S. Pat. App. 13/796,004, 2014.

(19) Hu, B.; DeBruler, C.; Rhodes, Z.; Liu, T. L. Long-Cycling Aqueous Organic Redox Flow Battery (AORFB) toward Sustainable and Safe Energy Storage. J. Am. Chem. Soc. 2017, 139, 1207-1214.

(20) Prifti, H.; Parasuraman, A.; Winardi, S.; Lim, T. M.; Skyllas-Kazacos, M. Membranes for Redox Flow Battery Applications. Membranes (Basel) 2012, 2, 275-306.

(21) Krishnan, C. V.; Creutz, C.; Schwarz, H. A.; Sutin, N. Reduction Potentials for 2,2'Bipyridine and 1,10-Phenanthroline Couples in Aqueous Solutions. J. Am. Chem. Soc. 1983, $105,5617-5623$.

(22) Smith, R. M.; Hansen, D. E. The pH-Rate Profile for the Hydrolysis of a Peptide Bond. $J$. Am. Chem. Soc. 1998, 120, 8910-8913. 


\section{Electronic Supplementary Information}

\section{A Neutral pH Aqueous Organic/Organometallic Redox Flow Battery with Extremely High Capacity Retention}

Eugene S. Beh, ${ }^{\dagger, t}$ Diana De Porcellinis, ${ }^{\dagger, \#}$ Rebecca L. Gracia, ${ }^{\|}$Kay T. Xia, ${ }^{\|}$Roy G. Gordon, ${ }^{\dagger, t, *}$ and Michael J. Aziz ${ }^{\dagger *}$

$\dagger$ John A. Paulson School of Engineering and Applied Sciences, Harvard University, Cambridge, MA 02138, USA

$\$$ Department of Chemistry and Chemical Biology, Harvard University, Cambridge, MA 02138, USA

\# Department of Chemical Science and Technologies, University of Rome "Tor Vergata", Rome, Italy

" Harvard College, Cambridge, MA 02138, USA

* To whom correspondence should be addressed: gordon@chemistry.harvard.edu (Roy G. Gordon); maziz@harvard.edu (Michael J. Aziz). 
Table of Contents

\begin{tabular}{|l|c|}
\hline Description & Page Number \\
\hline Overview of neutral pH aqueous organic RFB chemistries to date & $\mathrm{S} 3$ \\
\hline Decomposition mechanisms of other molecular pH 7 RFB reactants & $\mathrm{S} 5$ \\
\hline Determination of reactant permeability across membrane & $\mathrm{S} 7$ \\
\hline Rotating Disk Electrode (RDE) measurements & $\mathrm{S} 9$ \\
\hline $\begin{array}{l}\text { Three-electrode cyclic voltammetry and cyclic voltammogram of FcCONH- } \\
\text { TMAP }\end{array}$ & $\mathrm{S} 12$ \\
\hline General cell cycling & $\mathrm{S} 13$ \\
\hline Electrochemical impedance spectroscopy (EIS) experiments & $\mathrm{S} 14$ \\
\hline Effect of oxygen permeation on capacity retention & $\mathrm{S} 15$ \\
\hline $\begin{array}{l}\text { Cycling performance of a BTMAP-Vi / BTMAP-Fc cell at a 1:1 reactant molar } \\
\text { ratio }\end{array}$ & $\mathrm{S} 17$ \\
\hline Cycling performance of a MV / BTMAP-Fc cell at a 1:1 reactant molar ratio & $\mathrm{S} 18$ \\
\hline Coulombic efficiency when cycling at high reactant concentrations & $\mathrm{S} 19$ \\
\hline High capacity retention cycling conditions & $\mathrm{S} 20$ \\
\hline NMR study of reactant stabilities & $\mathrm{S} 21$ \\
\hline General information for synthesis & $\mathrm{S} 22$ \\
\hline Synthesis and characterization of BTMAP-Vi and MTMAP & $\mathrm{S} 27$ \\
\hline Synthesis and characterization of BTMAP-Fc & $\mathrm{S} 29$ \\
\hline Synthesis and characterization of FcCONH-TMAP & $\mathrm{S} 33$ \\
\hline References & \\
\hline
\end{tabular}




\begin{tabular}{|c|c|c|c|c|c|c|c|}
\hline 㝘亳 & 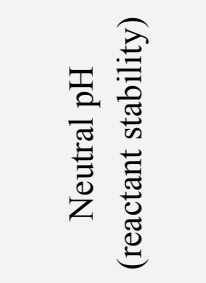 & 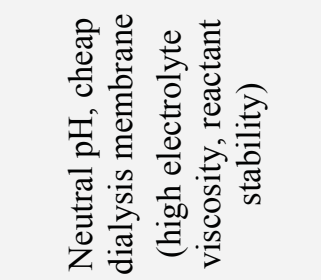 & 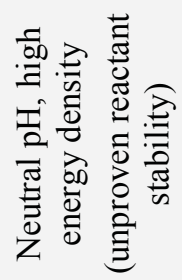 & $\begin{array}{l}\frac{\pi}{2} \\
\frac{\pi}{\pi} \\
\frac{\pi}{0} \\
\frac{0}{z}\end{array}$ & & \multicolumn{2}{|c|}{ 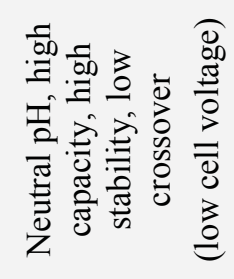 } \\
\hline 兽 & 玄 $\frac{\tilde{n}}{\stackrel{d}{d}}$ & 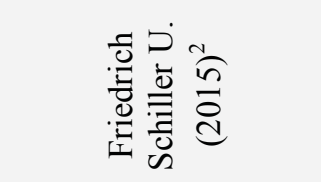 & 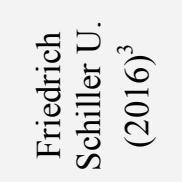 & \multicolumn{2}{|c|}{ 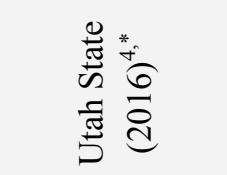 } & 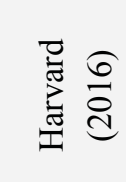 & 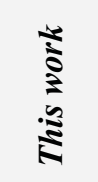 \\
\hline 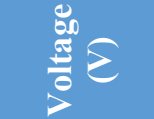 & $\stackrel{\text { }}{\dddot{n}}$ & $\exists$ & $\stackrel{\nabla}{-}$ & \multicolumn{2}{|c|}{$\stackrel{\text { }}{\circ}$} & \multicolumn{2}{|c|}{$\stackrel{n}{\tilde{0}}$} \\
\hline 路亏 & $\Xi$ & $=$ & $\stackrel{\infty}{m}$ & \multicolumn{2}{|c|}{ † } & \multicolumn{2}{|c|}{$\stackrel{i}{ }$} \\
\hline 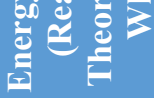 & $\underset{\infty}{+}$ & $\stackrel{\circ}{\circ}$ & $\stackrel{\infty}{m}$ & \multicolumn{2}{|c|}{$\hat{\sigma}$} & \multicolumn{2}{|c|}{$\stackrel{2}{=}$} \\
\hline 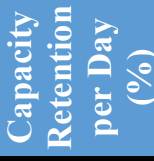 & $\frac{a}{\hat{a}}$ & 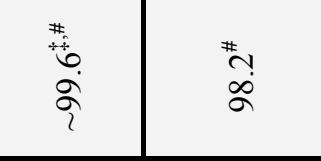 & $\stackrel{\text { \& }}{\stackrel{*}{a}}$ & 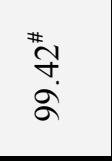 & 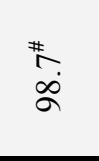 & $\begin{array}{l}\hat{\circ} \\
\text { aे }\end{array}$ & $\begin{array}{l}\text { ลे } \\
\text { ลे }\end{array}$ \\
\hline 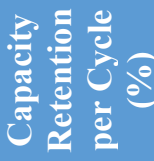 & $\begin{array}{l}\ddot{0} \\
\infty \\
a \\
\grave{a}\end{array}$ & 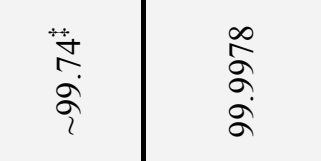 & $\begin{array}{l}\text { तै } \\
\text { वे } \\
\text { के }\end{array}$ & $\begin{array}{l}\hat{\infty} \\
\hat{a} \\
\alpha\end{array}$ & 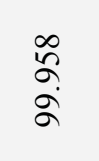 & $\begin{array}{l}\text { के } \\
\text { مे } \\
\text { aे }\end{array}$ & $\begin{array}{l}\text { aे } \\
\text { aे }\end{array}$ \\
\hline 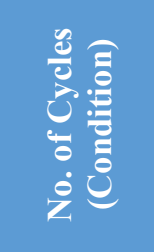 & 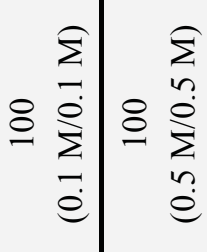 & 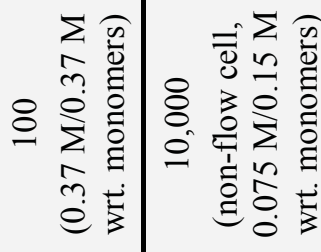 & 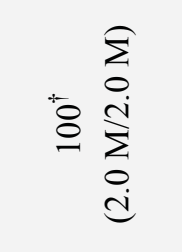 & 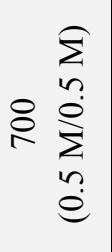 & 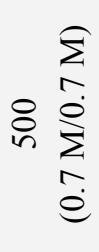 & 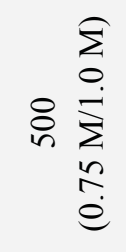 & 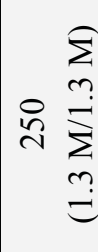 \\
\hline 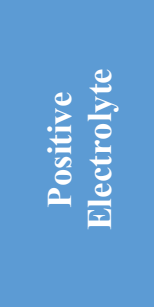 & 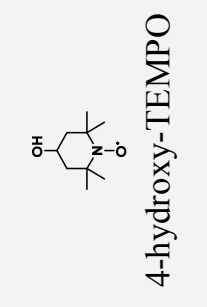 & 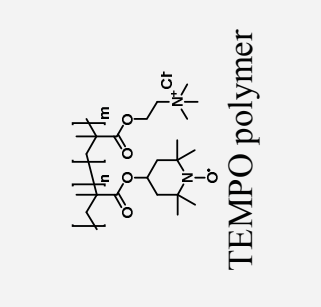 & 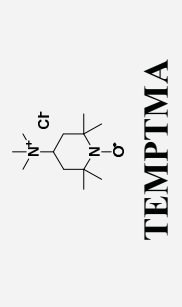 & 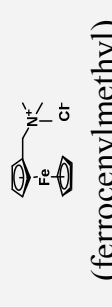 & 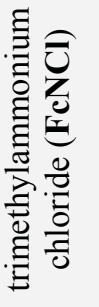 & $\sum_{0-0}^{2} \sum^{\prime}$ & $\frac{0}{0}$ \\
\hline 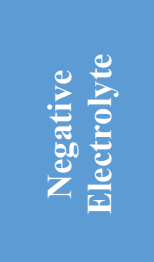 & 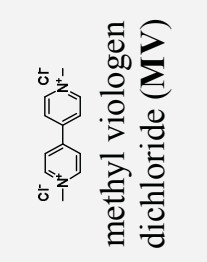 & 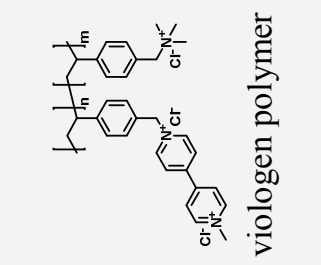 & 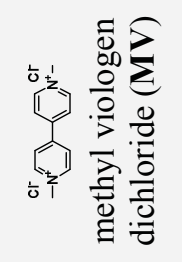 & 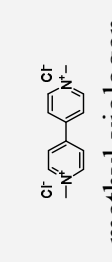 & $\left\{\begin{array}{l}\sum_{0}^{\infty} \\
\frac{0}{0} \\
\frac{0}{0} \\
\frac{0}{0}\end{array}\right.$ & 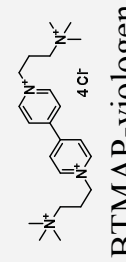 & ש̂. \\
\hline
\end{tabular}




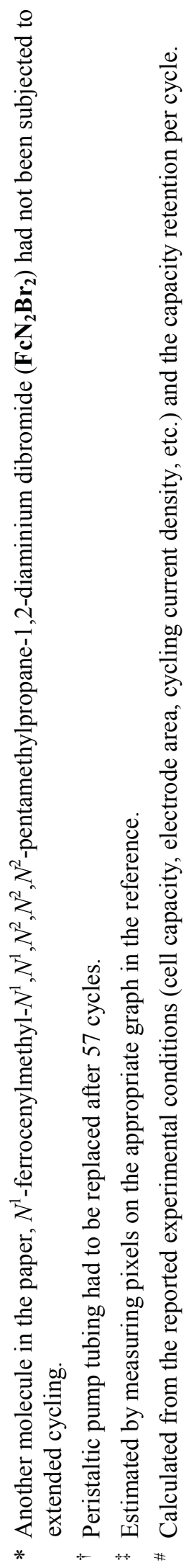


Decomposition mechanisms of other molecular pH 7 RFB reactants. During cell cycling with an initial $\mathrm{pH}$ of 7, 4-hydroxy-TEMPO (TEMPOL) decomposes, and the rate is accelerated at high TEMPOL concentrations. This manifests as a rapid capacity fade that is more severe at high posolyte concentrations. ${ }^{1,5}$ The loss of redox-active TEMPOL molecules arises from the reaction of TEMPOL ${ }^{+}$, the oxidized form of the molecule, with hydroxide. The resulting consumption of $\mathrm{OH}^{-}$ions results in a gradual acidification of the posolyte. In turn, TEMPOL undergoes a disproportionation reaction in the presence of $\mathrm{H}^{+}$to form TEMPOL ${ }^{+}$and 1,4-dihydroxy-2,2,6,6tetramethylpiperidine. The disproportionation is second order with respect to TEMPOL and is therefore faster at higher posolyte concentrations. It is presumable that other water-soluble TEMPO derivatives will decompose in the same way when cycled in a cell.

In the negolyte, during cell charging the dication $\mathrm{MV}^{2+}$ is reduced to the cation radical, $\mathrm{MV}^{\circ+}$. $\mathrm{MV}^{\circ+}$ is readily oxidized back to $\mathrm{MV}^{2+}$ by molecular oxygen, forming superoxide anion $\left(\mathrm{O}_{2}{ }^{-}\right)$ which eventually leads to a reduction in the overall state of charge (SOC) of the negolyte solution and the accumulation of hydroxide ions $\left(\mathrm{OH}^{\urcorner}\right){ }^{6}$ The overall reaction is:

$$
4 \mathrm{MV}^{\bullet+}+\mathrm{O}_{2}+2 \mathrm{H}_{2} \mathrm{O} \longrightarrow 4 \mathrm{MV}^{2+}+4 \mathrm{OH}^{-}
$$

The hydroxide ions so formed can deprotonate one of the methyl groups of $\mathrm{MV}^{2+}$, which eventually leads to the demethylation of $\mathrm{MV}^{2+}$ via a complex mechanism to form 1-methyl-[4,4'bipyridin]-1-ium chloride, a redox-inactive species. ${ }^{7}$ The methyl group is lost as formaldehyde.

Another mechanism for the decomposition of $\mathrm{MV}^{\circ+}$ is operative even if oxygen is strictly excluded. $\mathrm{MV}^{\circ+}$ dimerizes ${ }^{8-9}$ in aqueous solution with an association constant of $385 \mathrm{M}^{-1}$; this dimer can undergo disproportionation $\left(K_{\text {dis }}=1 \times 10^{-6}\right)$ to form $\mathrm{MV}^{2+}$ and the doubly reduced quinoid $\mathrm{MV}^{0}$, the latter of which can be irreversibly protonated to form another redox-inactive species. ${ }^{10-11}$ (Besides its insolubility in water arising from its lack of charge, this vulnerability of $\mathrm{MV}^{0}$ to protonation by water has precluded its exploitation as a charge-storage reactant for RFBs.) This second mechanism is expected to predominate when nitroxide radicals are employed in the posolyte because their decomposition upon cycling is accompanied by a decrease in the solution $\mathrm{pH}$ (see above).

On the other hand, ferrocene derivatives such as BTMAP-Fc are redox-active and chemically stable in acidic-to-neutral water in either oxidation state, as long as they are protected from oxygen. ${ }^{12-13}$ The oxidized (ferrocenium) form is decomposed by oxygen via a mechanism that involves the reaction of two ferrocenium species with each other, ${ }^{12}$ but alkyl or 1,1'dialkylferrocenium derivatives such as BTMAP-Fc are significantly more stable in aqueous solution than unsubstituted ferrocenium. ${ }^{14}$ One notable exception is (ferrocenylmethyl)trimethylammonium salts such as FcNCl. The close proximity of the quaternary ammonium group to the ferrocene center ( 1 methylene unit) causes (ferrocenylmethyl)trimethylammonium 
salts to be vulnerable to nucleophilic attack, losing trimethylamine as a leaving group in the process. ${ }^{15-16}$ 
Determination of Reactant Permeability through Membrane. To measure permeability, redox active species were placed in the donating side of a two-elbowed glass cell, where the membrane was sandwiched in between. A $0.2 \mathrm{M}$ solution of MV, BTMAP-Vi, or BTMAP-Fc in deionized water placed on the donating side was paired with either $0.8 \mathrm{M} \mathrm{NaCl}$ or $0.4 \mathrm{M} \mathrm{NaCl}$ solution respectively on the receiving side, which ensured that water crossover in either direction was minimized. To keep the solutions under agitation, the cell was placed on a nutating table.

At regular intervals over the course of $\sim 6$ weeks, $10 \mu \mathrm{L}$ aliquots of the solution on the receiving side were diluted to $2.00 \mathrm{~mL}$ in $0.4 \mathrm{M} \mathrm{NaCl}$ or $0.8 \mathrm{M} \mathrm{NaCl}$ solution. UV-visible analysis (Ocean Optics Flame-S Spectrometer Assembly) allowed the concentrations of MV, BTMAP-Vi, or BTMAP-Fc that had crossed over to the receiving side to be determined. The permeability coefficient $P$ was calculated from the equation ${ }^{18}$

$$
P=\frac{\ln \left(1-\frac{2 C_{r}}{C_{0}}\right)\left(-\frac{V l}{2 A}\right)}{t}
$$

where $C_{\mathrm{r}}$ is the concentration measured at the receiving reservoir, $C_{0}$ is the active species concentration in the donating reservoir $(0.2 \mathrm{M}), V$ is the volume of the receiving side $(5 \mathrm{~mL}), l$ is the membrane thickness $(110 \mu \mathrm{m}), A$ is the membrane area $\left(0.66 \mathrm{~cm}^{2}\right)$, and $t$ is the time.

The impact of reactant crossover on capacity loss is summarized in Table S2 and Figure S1. According to the permeability coefficients determined above, the duration before reactant crossover results in a $10 \%$ (or 50\%) loss of capacity for an assumed future set of conditions can be calculated using the equations

or

$$
\tau_{90 \%}=\frac{i_{c} l t_{d} \ln \left(\frac{1}{0.9}\right)}{P C n F}
$$

$$
\tau_{50 \%}=\frac{i_{c} l t_{d} \ln \left(\frac{1}{0.5}\right)}{P C n F}
$$

where $i_{c}$ is the cycling current density $\left(100 \mathrm{~mA} \mathrm{~cm}^{-2}\right), t_{d}$ is the discharge time ( $8 \mathrm{~h}$ or $\left.28800 \mathrm{~s}\right), C$ is the concentration of electroactive species $\left(1 \mathrm{M}\right.$ or $\left.1 \times 10^{-3} \mathrm{~mol} \mathrm{~cm}^{-3}\right), n$ is the number of electrons per mole of redox-active species $\left(1 \mathrm{e}^{-}\right)$, and $F$ is Faraday's constant. 
Table S2. Crossover of MV, BTMAP-Vi and BTMAP-Fc across a Selemion DSV membrane.

\begin{tabular}{|c|c|c|c|}
\hline & $\begin{array}{c}\text { Permeability coefficient / } \\
\mathrm{cm}^{2} \mathrm{~s}^{-1}\end{array}$ & $\begin{array}{c}\text { Time to 10\% } \\
\text { capacity loss / years }\end{array}$ & $\begin{array}{c}\text { Time to 50\% } \\
\text { capacity loss / years }\end{array}$ \\
\hline MV & $3.4 \times 10^{-9}$ & 0.3 & 2.1 \\
\hline BTMAP-Vi & $6.7 \times 10^{-10}$ & 1.6 & 10.8 \\
\hline BTMAP-Fc & $6.2 \times 10^{-10}$ & 1.8 & 11.6 \\
\hline
\end{tabular}

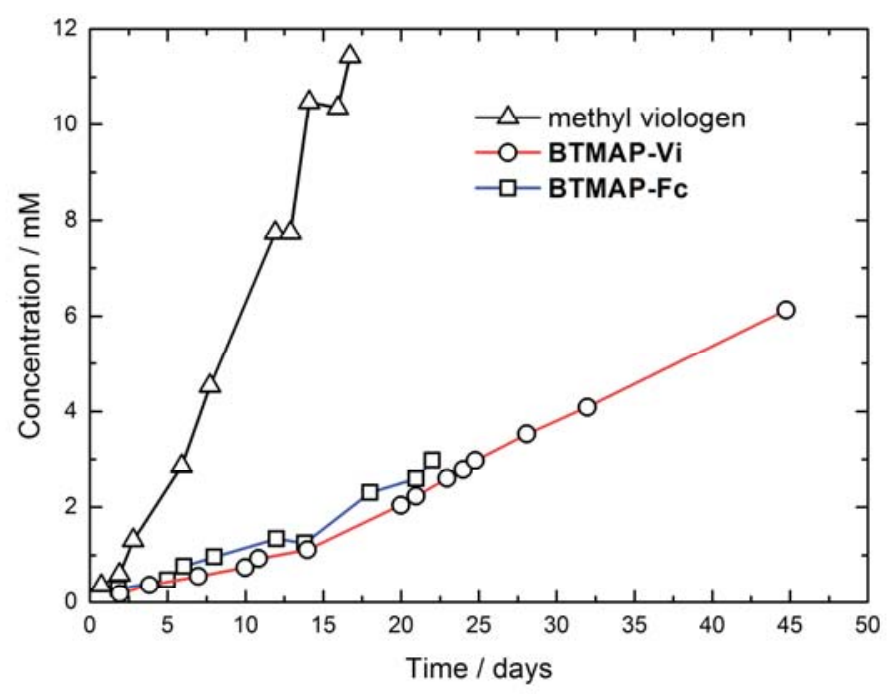

Figure S1. Crossover tests for methyl viologen dichloride (MV), BTMAP-Vi, and BTMAP-Fc across a Selemion DSV membrane. The permeability coefficient for each species can be calculated from the rate of increase in concentration of each species in the receiving side. 
Rotating Disk Electrode (RDE) measurements. RDE experiments were conducted using a Pine Instruments Modulated Speed Rotator AFMSRCE equipped with a $5 \mathrm{~mm}$ diameter glassy carbon working electrode, a $\mathrm{Ag} / \mathrm{AgCl}$ reference electrode (BASi, pre-soaked in $3 \mathrm{M} \mathrm{NaCl}$ solution), and a platinum wire counter electrode. The electrode was rotated at a specific speed while the voltage was linearly swept from -0.10 to $-0.75 \mathrm{~V} v s$. $\mathrm{Ag} / \mathrm{AgCl}$ (for BTMAP-Vi), or from -0.10 to $+0.50 \mathrm{~V}$ vs. $\mathrm{Ag} / \mathrm{AgCl}$ (for BTMAP-Fc). The reduction rate constant of BTMAP$\mathbf{V i}$ and the oxidation rate constant of BTMAP-Fc were calculated from the Tafel equation using the following parameters: $n=1$; Faraday's constant $F=96,485 \mathrm{C} \mathrm{mol}^{-1}$; electrode area $A=$ $0.1963 \mathrm{~cm}^{2}$; BTMAP-Fc or BTMAP-Vi concentration $C=1.00 \times 10^{-6} \mathrm{~mol} \mathrm{~cm}^{-3}$; kinematic viscosity of $0.50 \mathrm{M} \mathrm{NaCl} v=0.01024 \mathrm{~cm}^{2} \mathrm{~s}^{-1}$, temperature $T=293 \mathrm{~K}$. The experiment was performed three times. Results are summarized in Figure S2 and Figure S3.
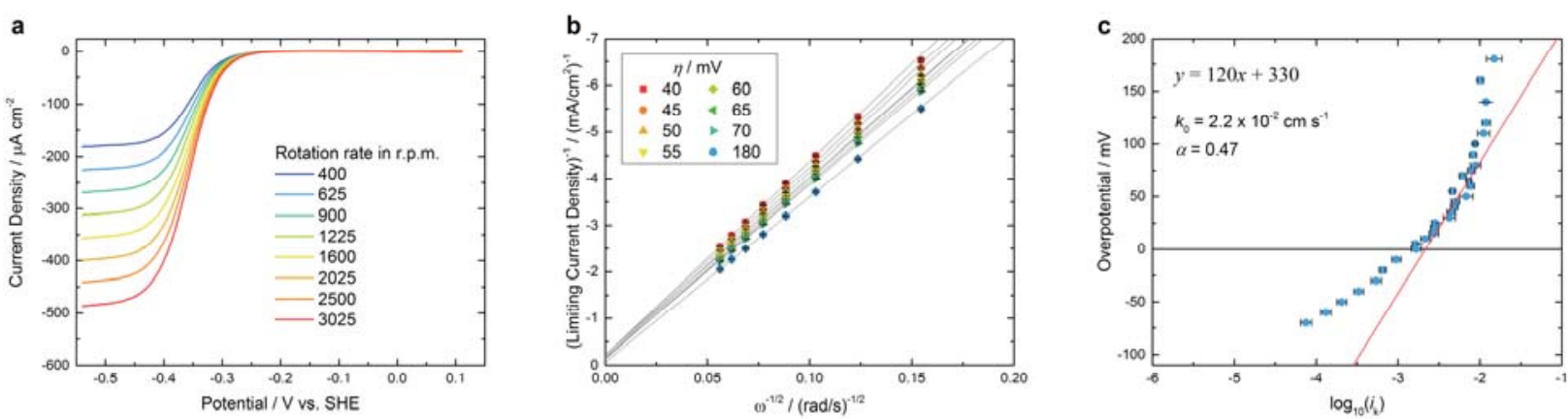

Figure S2. (a) Plot of potential vs. current density at different rotation rates of the rotating disk electrode (RDE). The solution is $1.00 \mathrm{mM} \mathrm{BTMAP-Vi}$ and $0.50 \mathrm{M} \mathrm{NaCl}$ in $\mathrm{H}_{2} \mathrm{O}$. Rotation rates are indicated. (b) Koutecký-Levich plot $\left(i^{-1} v s . \omega^{-1 / 2}\right)$ of $1.00 \mathrm{mM}$ BTMAP-Vi and $0.50 \mathrm{M} \mathrm{NaCl}$ in $\mathrm{H}_{2} \mathrm{O}$. The current response, $i^{-1}$, is shown for eight different BTMAP-Vi reduction overpotentials $\eta$. (c) Fit of RDE experimental data to the Butler-Volmer equation constructed using the current response in the absence of mass transport limitations at high BTMAP-Vi reduction overpotentials; $i_{\mathrm{k}}$ is the current extrapolated from the zero-intercept of the fitted lines in (b) (i.e. at infinite rotation rate). The line of best fit to the region between an overpotential of $40-80 \mathrm{mV}$ has the equation $y=120 x+330$, from which $\alpha=0.47$ and $k_{0}=2.2 \times 10^{-2} \mathrm{~cm} \mathrm{~s}^{-1}$ were calculated. Data were averaged over three runs. 

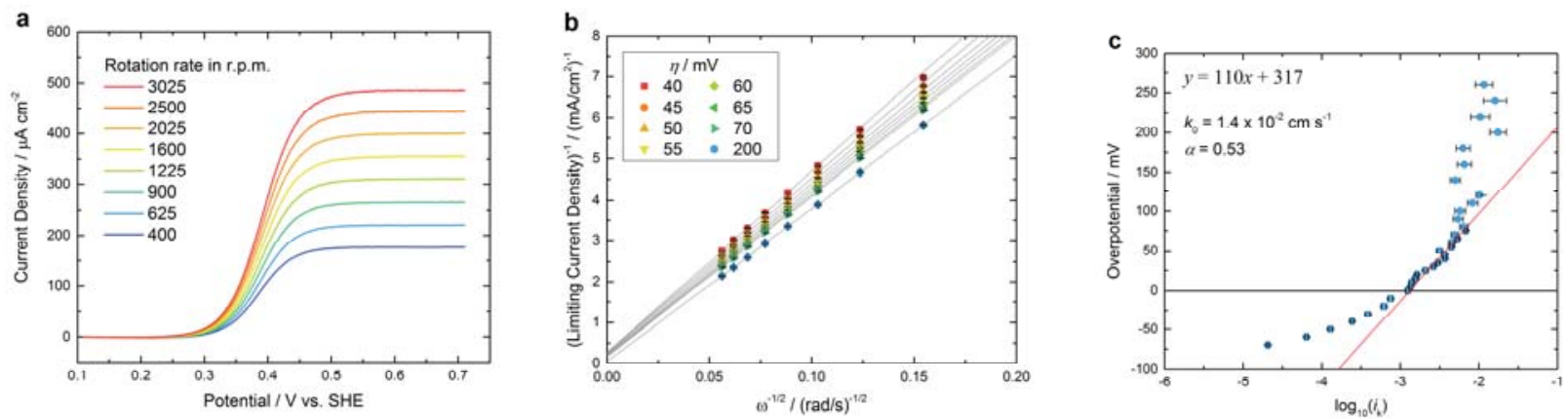

Figure S3. (a) Plot of potential vs. current density at different rotation rates of the rotating disk electrode (RDE). The solution is $1.00 \mathrm{mM}$ BTMAP-Fc and $0.50 \mathrm{M} \mathrm{NaCl}$ in $\mathrm{H}_{2} \mathrm{O}$. Rotation rates are indicated. (b) Koutecký-Levich plot $\left(i^{-1} v s . \omega^{-1 / 2}\right)$ of $1.00 \mathrm{mM}$ BTMAP-Fc and $0.50 \mathrm{M} \mathrm{NaCl}$ in $\mathrm{H}_{2} \mathrm{O}$. The current response, $i^{-1}$, is shown for eight different BTMAP-Fc oxidation overpotentials $\eta$. (c) Fit of RDE experimental data to the Butler-Volmer equation constructed using the current response in the absence of mass transport limitations at low BTMAP-Fc oxidation overpotentials; $i_{\mathrm{k}}$ is the current extrapolated from the zero-intercept of the fitted lines in (b) (i.e. at infinite rotation rate). The line of best fit to the region between an overpotential of $40-80 \mathrm{mV}$ has the equation $y=110 x+317$, from which $\alpha=0.53$ and $k_{0}=1.4 \times 10^{-2} \mathrm{~cm} \mathrm{~s}^{-1}$ were calculated. Data were averaged over three runs. 
Cyclic voltammetry. Three-electrode cyclic voltammetry tests were performed using a glassy carbon electrode (5.0 mm diameter), a $\mathrm{Ag} / \mathrm{AgCl}$ reference electrode ( $\mathrm{BASi}$, presoaked in $3 \mathrm{M}$ $\mathrm{NaCl}$ solution), and a platinum wire counter electrode. Cyclic voltammograms of BTMAP-Vi and BTMAP-Fc are shown in Main Text Figure 1; the cyclic voltammogram of FcCONHTMAP is shown below in Figure S4.

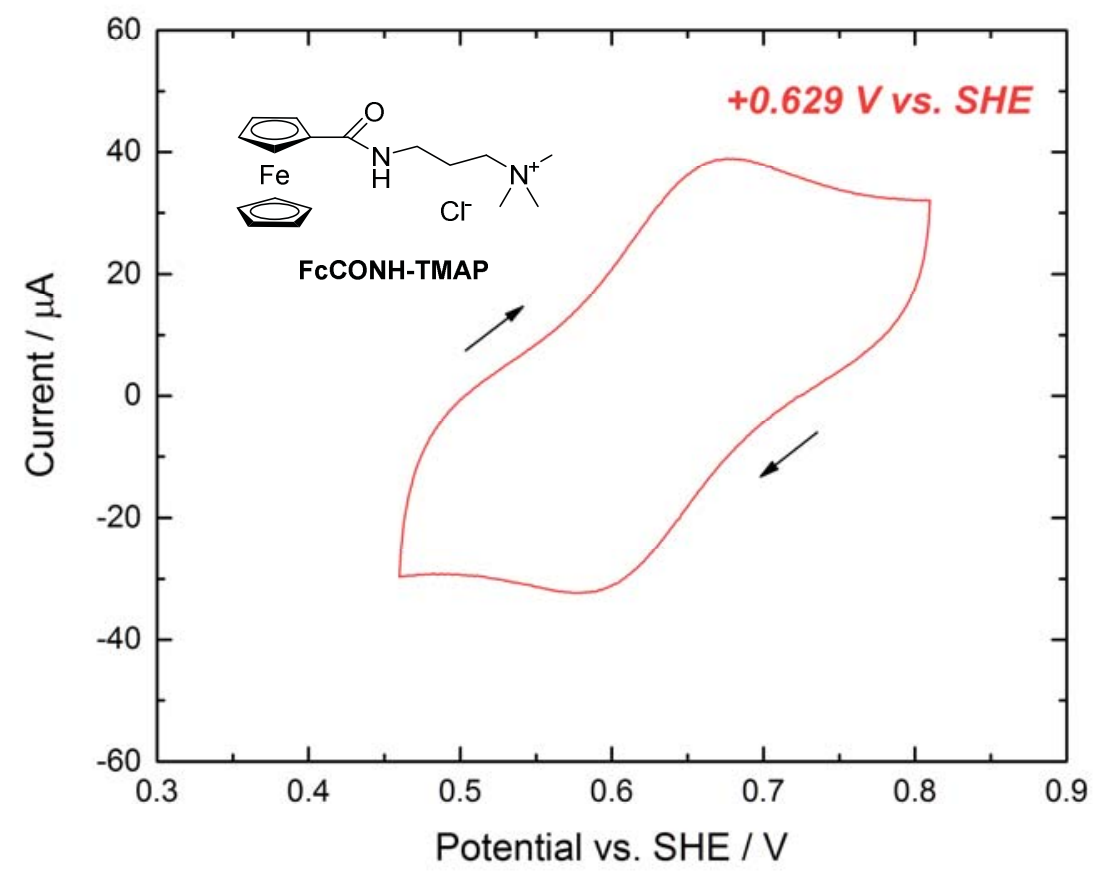

Figure S4. Cyclic voltammogram of FcCONH-TMAP. Conditions: $1 \mathrm{mM}$ in $0.5 \mathrm{M}$ $\mathrm{NaCl}, 100 \mathrm{mV} \mathrm{s}^{-1}$ sweep rate. The $10^{\text {th }}$ cycle is shown. 
General cell cycling. For the full cell measurements, cell hardware from Fuel Cell Tech was used to assemble a zero-gap flow cell configuration, similar to what was previously reported. ${ }^{17}$ POCO graphite flow plates with serpentine flow fields were used for both sides.

Electrodes of $5 \mathrm{~cm}^{2}$ geometric surface area comprised a stack of four sheets of Sigracet SGL 39AA porous carbon paper, which had been pretreated by baking in air at $400{ }^{\circ} \mathrm{C}$ for $24 \mathrm{~h}$. A sheet of Selemion DSV membrane (Asahi Glass Co., Ltd.), which had been stored in $0.25 \mathrm{M}$ $\mathrm{NaCl}$ solution, served as the ion-selective membrane. The rest of the space was gasketed by Viton sheets. The electrolytes were fed into the cell through FEP tubing, at a rate of $60 \mathrm{~mL} \mathrm{~min}^{-1}$ controlled by Cole-Parmer Masterflex L/S peristaltic pumps. Cyclic voltammetry and rotating disk electrode voltammetry (see below) were performed using a Gamry Reference 3000 potentiostat. Cell polarization, impedance spectroscopy measurements, and charge-discharge cycling were performed using a BioLogic BCS-815 battery cycling system or a Gamry Reference 3000 potentiostat.

Where employed, galvanostatic charging and discharging of a full electrochemical cell was performed at the predefined current densities until the cell voltage rose or fell to $1.1 \mathrm{~V}$ or $0.3 \mathrm{~V}$ respectively, after which there would be a 10 -second hold at open circuit potential before the next half-cycle (charge or discharge). For galvanostatic cycling with potential holds, cycling was done as described above but once the predefined potential cutoffs were reached, the cell was maintained at the same voltage until the magnitude of the charging or discharging current density had decreased to $1 \mathrm{~mA} \mathrm{~cm}^{-2}$. A 10 -second hold at open circuit potential followed by the next cycling step would then proceed as before. 
Electrochemical impedance spectroscopy (EIS) experiments. EIS was performed by applying a sine voltage waveform of amplitude $10 \mathrm{mV}$ added to an offset voltage (open circuit voltage for measurements in Figure 2 $\mathbf{b},+0.3 \mathrm{~V}$ in all other cases). The frequency of the sine voltage was varied stepwise from $300 \mathrm{kHz}$ to $10 \mathrm{~Hz}$, with 10 points per decade in logarithmic spacing. The real component of the impedance at the point where the imaginary component of the impedance was zero (i.e. the horizontal intercept of the Nyquist plot) was multiplied by the geometric electrode area $\left(5 \mathrm{~cm}^{2}\right)$ to obtain the high-frequency ASR. 
Effect of oxygen permeation on capacity retention. In order to demonstrate the effect of oxygen permeation into the cell, a cell was operated inside an air-filled glove bag. The reactants were $8.00 \mathrm{~mL}$ of negolyte containing $0.75 \mathrm{M}$ BTMAP-Vi, and $6.00 \mathrm{~mL}$ of posolyte containing $1.00 \mathrm{M}$ BTMAP-Fc. Upon galvanostatic cycling at $40 \mathrm{~mA} \mathrm{~cm}^{-2}$, an induction period lasting roughly 10 cycles was seen, after which the rate of capacity decrease became steadier and the Coulombic efficiency stabilized. The steep drop in capacity during the first 10 cycles is attributed to the consumption by reduced BTMAP-Vi of all oxygen present in the reservoir headspace and dissolved in the electrolyte solutions. (Figure S5) At cycle 51, the glove bag was purged and filled with nitrogen, causing an immediate halt to the capacity fade and a jump in the Coulombic efficiency to above $99.9 \%$.

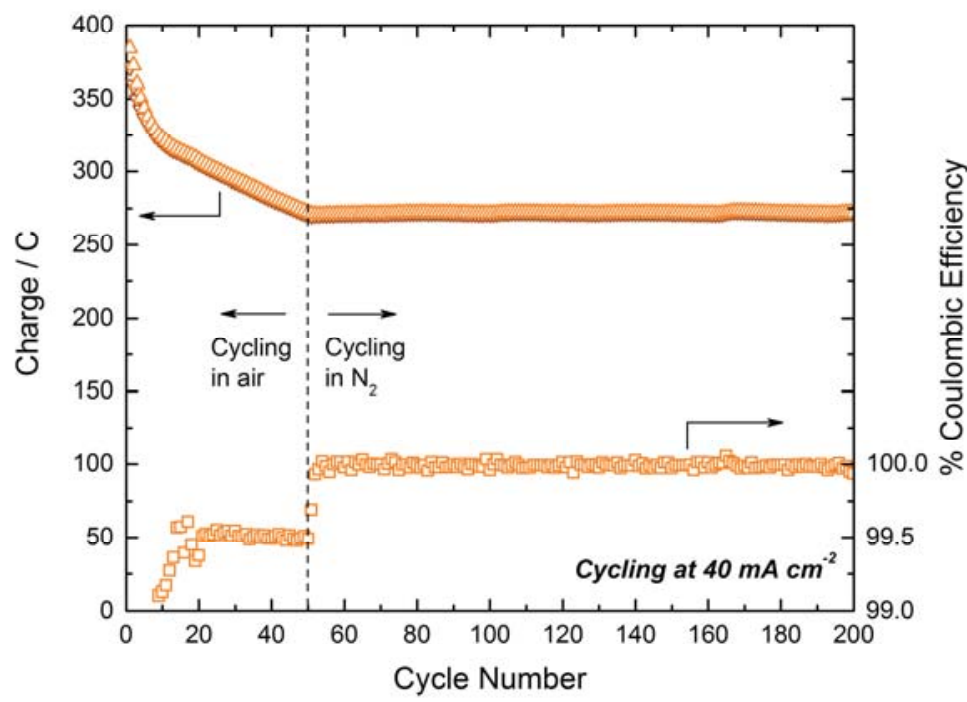

Figure S5. Cycling of a different BTMAP-Vi / BTMAP-Fc $\mathrm{pH} 7$ cell at $40 \mathrm{~mA} \mathrm{~cm}{ }^{-2}$. The cell was operated inside an air-filled glove bag for cycles $1-50$, then the glove bag was purged and filled with $\mathrm{N}_{2}$ for cycles $50-150$. Top traces, left axis: Evolution of the cell charge (upward-pointing triangles) and discharge (downward-pointing triangles) capacity as functions of cycle number. Bottom traces, right axis: Coulombic efficiency of the cell for each charge-discharge cycle (squares). 
Cell cycling with a 1:1 molar ratio of reactants. Another cell was constructed in the same way as described on Page S14. This time, the glove bag was filled with nitrogen before any cycling took place. 100 galvanostatic charge-discharge cycles with potential holds were performed successively for each of three current densities: $100 \mathrm{~mA} \mathrm{~cm}^{-2}, 50 \mathrm{~mA} \mathrm{~cm}{ }^{-2}$, and $25 \mathrm{~mA} \mathrm{~cm}^{-2}$. The results are summarized below in Figure S6 and Table S3.
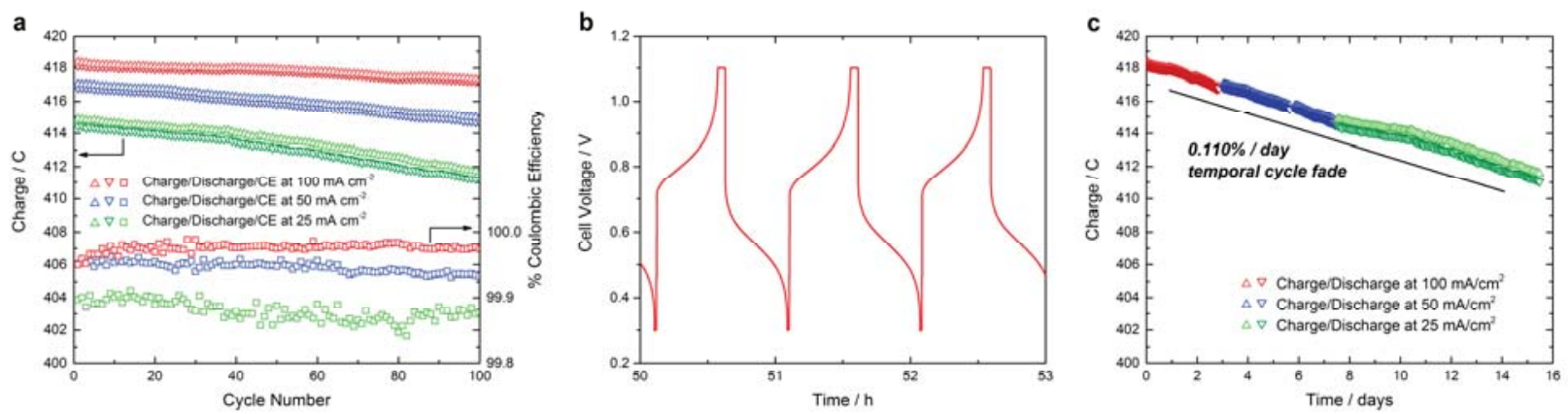

Figure S6 (a) Extended cell cycling study at three different current densities conducted successively: $100 \mathrm{~mA} \mathrm{~cm}^{-2}$ (red symbols), $50 \mathrm{~mA} \mathrm{~cm}^{-2}$ (blue symbols), and $25 \mathrm{~mA} \mathrm{~cm}^{-2}$ (green symbols). Top traces, left axis: Evolution of the cell charge and discharge capacity vs. cycle number. Bottom traces, right axis: Coulombic efficiency of the cell for each charge-discharge cycle. (b) Representative voltage vs. time curves during cycling at $50 \mathrm{~mA} \mathrm{~cm}^{-2}$, recorded between the $50^{\text {th }}$ and $53^{\text {rd }}$ hour of cycling. (c) The same data as in Figure S6a, plotted as a function of time.

As before, a short induction period (the first 10 cycles) was observed before the Coulombic efficiency stabilized. The capacity retention at each of the different current densities was well over $99.99 \%$ / cycle for all three current densities, up to $99.9977 \% /$ cycle at $100 \mathrm{~mA} \mathrm{~cm}^{-2}$. Furthermore, the average Coulombic efficiency was exceptionally high at $99.976 \%$ (see Table S3). In general, higher current densities are associated with the shorter cycle periods, as well as higher capacity retention and Coulombic efficiency, but these numbers come at the expense of the round-trip energy efficiency due to the high membrane ASR.

By representing the cycling data as a function of time starting at the beginning of the experiment (Figure S6c), it is apparent that the temporal cycle fade rate is essentially independent of the cycling current density. This suggests that a chemical, rather than an electrochemical, mechanism is mostly responsible for the observed capacity fade of the BTMAP-Vi/BTMAP-Fc system. (We regard the continued reaction of reduced BTMAP-Vi and oxidized BTMAP-Fc with oxygen from the environment as a chemical mechanism; see the discussion of reactant stability on Page S5 for details.) 
Table S3. Average capacity retention per cycle and Coulombic efficiency of the $\mathrm{pH} 7$ cell at three different current densities.

\begin{tabular}{|l|c|c|c|}
\hline Current density & $25 \mathrm{~mA} \mathrm{~cm}^{-2}$ & $50 \mathrm{~mA} \mathrm{~cm}^{-2}$ & $100 \mathrm{~mA} \mathrm{~cm}^{-2}$ \\
\hline $\begin{array}{l}\text { Capacity retention } \\
\text { per cycle }\end{array}$ & $\begin{array}{c}99.9921 \% / \\
\text { cycle }\end{array}$ & $\begin{array}{c}99.9948 \% / \\
\text { cycle }\end{array}$ & $\begin{array}{c}99.9977 \% / \\
\text { cycle }\end{array}$ \\
\hline $\begin{array}{l}\text { Coulombic } \\
\text { efficiency }\end{array}$ & $99.880 \%$ & $99.946 \%$ & $99.976 \%$ \\
\hline $\begin{array}{l}\text { Round-trip energy } \\
\text { efficiency }\end{array}$ & $81.1 \%$ & $66.3 \%$ & $44.2 \%$ \\
\hline Time per cycle & $113 \mathrm{~min}$ & $61 \mathrm{~min}$ & $32 \mathrm{~min}$ \\
\hline
\end{tabular}


Cell cycling of MV vs. BTMAP-Fc. To see how BTMAP-Vi performs as a low-potential reactant relative to MV, a cell was constructed the same way as described on Page S15, except that the negolyte comprised $0.75 \mathrm{M}$ of MV dissolved in water instead of $0.75 \mathrm{M}$ of BTMAP-Vi, and the experiment was conducted inside an argon-filled glove box instead of a nitrogen-filled glove bag. 100 galvanostatic charge-discharge cycles with potential holds were performed at a current density of $50 \mathrm{~mA} \mathrm{~cm}{ }^{-2}$. (Figure S7) These conditions were identical to those used to collect the data in Figure $\mathbf{S 6}$ at a current density of $50 \mathrm{~mA} \mathrm{~cm}$. The 100 cycles required 4.37 days to complete, or 63 minutes per cycle on average. The capacity retention rate was found to be $99.938 \%$ / cycle, or $98.60 \%$ / day, at a Coulombic efficiency of $99.88 \%$. The corresponding capacity fade rates were $0.062 \%$ / cycle and $1.40 \%$ / day. These fade rates are more than an order of magnitude higher than when BTMAP-Vi was used in the negolyte.

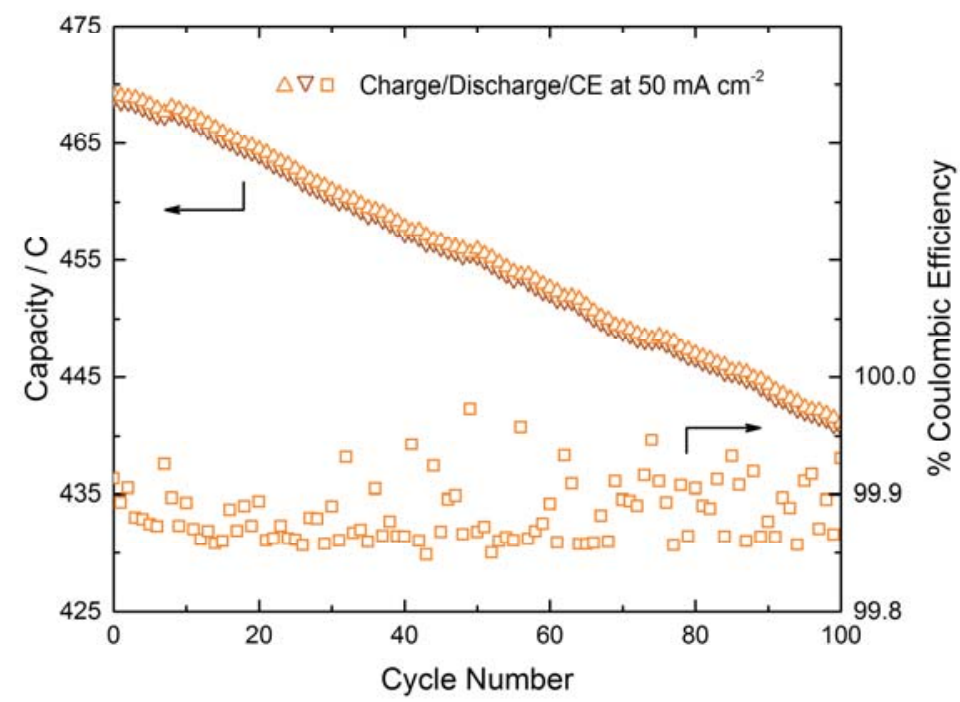

Figure S7. Extended cell cycling study of MV $v s$. BTMAP-Fe at a current density of $50 \mathrm{~mA} \mathrm{~cm}{ }^{-2}$. Top traces, left axis: Evolution of the cell charge and discharge capacity $v s$. cycle number. Bottom traces, right axis: Coulombic efficiency of the cell for each chargedischarge cycle. 
Coulombic efficiency when cycling at high reactant concentrations. The capacity of a high concentration BTMAP-Vi/BTMAP-Fc RFB during extended cycling was presented in Main Text Figure 3. Figure S8 shows the same capacity data, but includes the Coulombic efficiency for each cycle instead of the high-frequency ASR every 10 cycles.

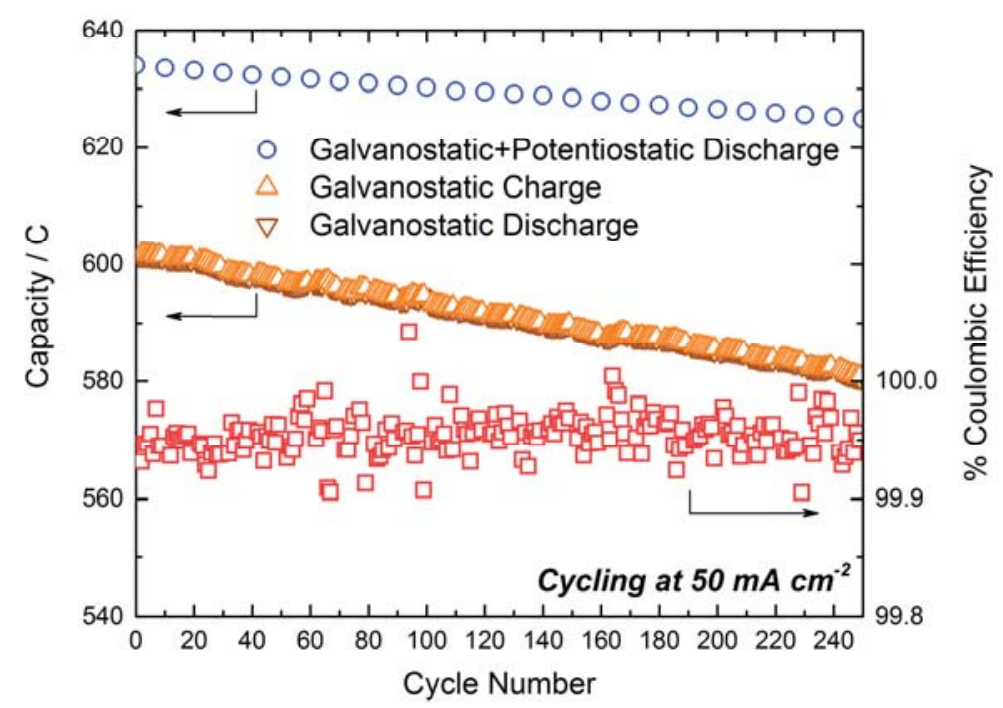

Figure S8. Evolution of the capacity of the BTMAP-Vi/BTMAP-Fc RFB at a concentration of $1.3 \mathrm{M} / 1.3 \mathrm{M}$ during extended cell cycling at $50 \mathrm{~mA} \mathrm{~cm}^{-2}$ (orange and brown triangles, left axis). At every $10^{\text {th }}$ cycle, the potential was maintained at the end of each charge or discharge until the current fell below $1 \mathrm{~mA} \mathrm{~cm}^{-2}$ (blue circles, left axis). This capacity data is identical to Figure 3a. The Coulombic efficiency for the galvanostatic cycling, excluding the cycles immediately after the potential holds, is also indicated (red squares, right axis). 
Comparison of capacity fade rates during purely galvanostatic cycling. The data represented by the orange and brown triangles in Main Text Figure 3a and in Figure S8 were results based solely on galvanostatic cycling, and not galvanostatic cycling followed by a short potential hold (blue circles). The data may also be thought of as coming from twenty-five successive galvanostatic cycling experiments, each starting at $0 \%$ SOC and proceeding for nine cycles at a constant charge-discharge current density of $50 \mathrm{~mA} \mathrm{~cm}$. The number of consecutive cycles is small, but the large number of experiments (25) allows the capacity retention under galvanostatic cycling conditions to be determined to a high degree of certainty. The data for this experiment are presented in Figure S9.

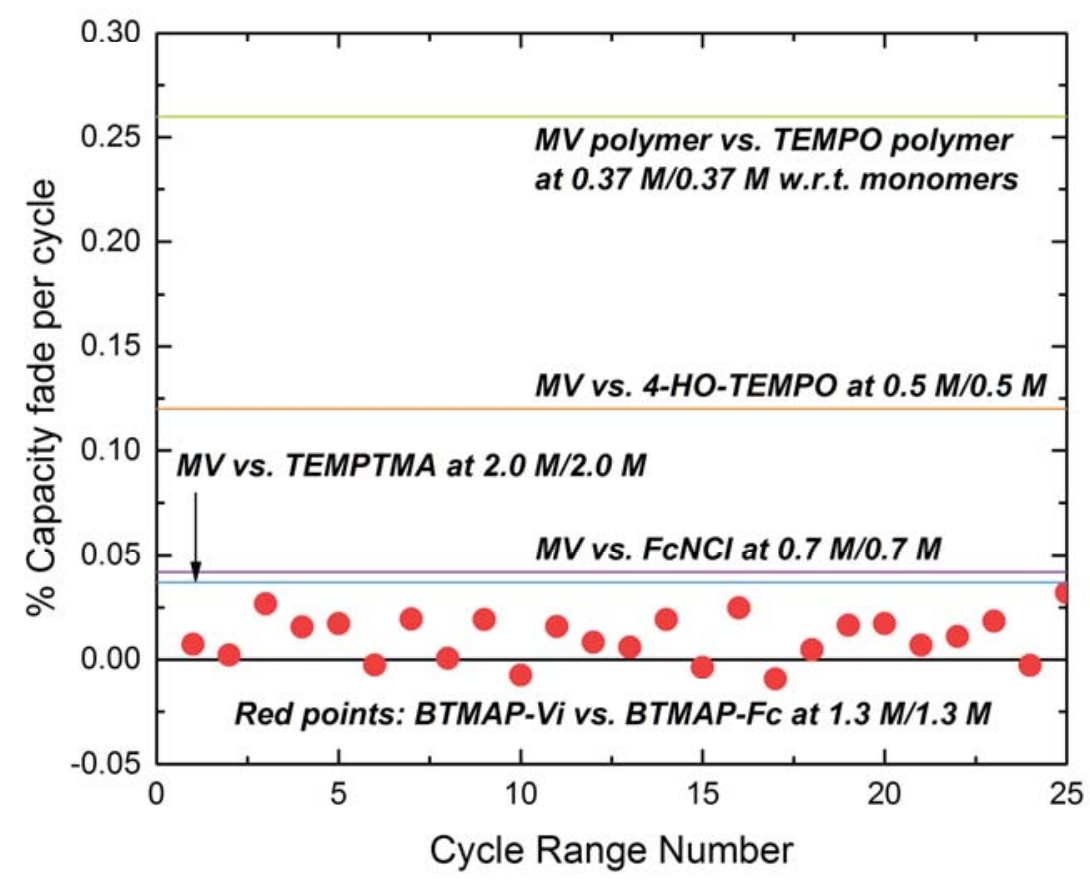

Figure S9. Capacity fade rate per cycle for each of the twenty-five periods of galvanostatic cycling in Main Text Figure 3a and Figure S8. Each period of galvanostatic cycling consists of nine charge-discharge cycles at a current density of 50 $\mathrm{mA} \mathrm{cm}{ }^{-2}$. Horizontal colored lines indicate the capacity fade rates of other $\mathrm{pH} 7 \mathrm{RFB}$ chemistries reported in the literature and summarized in Table S1.

The average capacity fade rate is $(0.011 \pm 0.011) \%$ /cycle, or $(0.19 \pm 0.19) \% /$ day. Whether expressed as a function of cycle number or time, these numbers are still lower than for any of the pumped cell experiments in Table S1. Some periods of galvanostatic cycling see negative cycle fade rates because the membrane ASR shows small diurnal variations. A period of galvanostatic cycling associated with a decrease in membrane ASR will display smaller than average cycle fade rates. (See Main Text Figure 3a) Nevertheless, the long term galvanostatic capacity fade 
rate is higher than the fade rate of the absolute cell capacity (determined by galvanostatic cycling with potential holds) because the membrane resistance slowly rises over several weeks. 
High capacity retention cycling conditions. To set up the cell in Main Text Figure 4, a cell was set up as described on Page S15 in a nitrogen-filled glove bag with $8.00 \mathrm{~mL}$ of negolyte containing $0.75 \mathrm{M}$ BTMAP-Vi, and $6.00 \mathrm{~mL}$ of posolyte containing $1.00 \mathrm{M}$ BTMAP-Fc. Both posolyte and negolyte were charged to $100 \%$ SOC by the application of a constant voltage of $1.1 \mathrm{~V}$ until the current density fell below $1 \mathrm{~mA} \mathrm{~cm}^{-2}$. Once this was achieved, small volumes of negolyte and posolyte were removed using a syringe fitted with a long stainless steel needle while the voltage of $1.1 \mathrm{~V}$ was still being applied to the cell, leaving a starting cell composition of $7.50 \mathrm{~mL}$ of negolyte containing $0.75 \mathrm{M}$ BTMAP-Vi and $3.25 \mathrm{~mL}$ of posolyte containing $1.00 \mathrm{M}$ BTMAP-Fc, both at $100 \%$ SOC. Cycling at $50 \mathrm{~mA} \mathrm{~cm}^{-2}$ then proceeded as described on Page S15. 
NMR study of reactant stabilities. After cell cycling for 300 cycles at various current densities, representing a total cycling time of more than 15 days (see Figure S6), the cell was charged to $\sim 100 \%$ SOC by applying a voltage of $1.1 \mathrm{~V}$ to the cell for two hours. At the end of the two hours, the two electrolyte solutions were analyzed immediately by NMR, then once more after storage in a $\mathrm{N}_{2}$ atmosphere for 1 week at room temperature. For each NMR analysis, a $10 \mu \mathrm{L}$ aliquot of BTMAP-Vi solution was withdrawn under oxygen-free conditions and diluted with $790 \mu \mathrm{L}$ of aerated $\mathrm{D}_{2} \mathrm{O}$. Similarly, a $20 \mu \mathrm{L}$ aliquot of BTMAP-Fc solution was diluted with $780 \mu \mathrm{L}$ of $\mathrm{D}_{2} \mathrm{O}$, then just enough solid $\mathrm{Na}_{2} \mathrm{~S}_{2} \mathrm{O}_{4}$ was added to remove all traces of paramagnetic BTMAP-Fc ${ }^{+}$to facilitate NMR analysis.

Figure S10 shows the NMR spectra of the two electrolyte solutions after various treatments. No trace of BTMAP-Fc could be detected in the BTMAP-Vi reservoir or vice versa, which is consistent with the low permeability of the reactants across the membrane, as determined on Page S7. In addition, no decomposition of reduced BTMAP-Fc, oxidized BTMAP-Fc, reduced BTMAP-Vi, or oxidized BTMAP-Vi could be seen when cycling was conducted in an argonfilled glove box. (See Main Text Figure 3 for experimental details.)

When the cell was cycled in a nitrogen-filled glove bag (see Figure S5), approximately 29\% of BTMAP-Vi was found to have decomposed to $N$-(3-trimethylammonio)propyl-4,4'-dipyrydyl dichloride (MTMAP) and (3-hydroxypropyl)trimethylammonium chloride after cycling had concluded. (See Page S25 for the synthesis of MTMAP.) The extent of dealkylation was consistent with the capacity of the cell at the start of cycling compared to what it should have been. With $8.00 \mathrm{~mL}$ of negolyte comprising $0.75 \mathrm{M}$ of BTMAP-Vi, the capacity should have been approximately $580 \mathrm{C}$ but only $418 \mathrm{C}$ was accessible, a deficit of $28 \%$. This result suggests that hydroxide, formed from contact of reduced BTMAP-Vi with oxygen prior to the completion of the first cycle, and to a lesser extent from more oxygen that enters the system from the glove bag environment in subsequent cycles, was responsible for the decomposition of the molecule. This hypothesis is supported by the observation that the cycled electrolyte showed no further decomposition when stored in a sealed container at $100 \%$ SOC under $\mathrm{N}_{2}$ without cycling. Furthermore, as noted earlier, no decomposition of BTMAP-Vi was seen by NMR (within instrument error) when the cycling was performed in an argon-filled glove box instead of the glove bag. It must be noted that ${ }^{1} \mathrm{H}$ NMR generally has a practical detection limit of $\sim 1 \%$ with respect to the major analyte; given the low capacity fade of the BTMAP-Vi/BTMAP-Fc chemistry, identification and detailed characterization of other minor decomposition products besides MTMAP by NMR is difficult. 

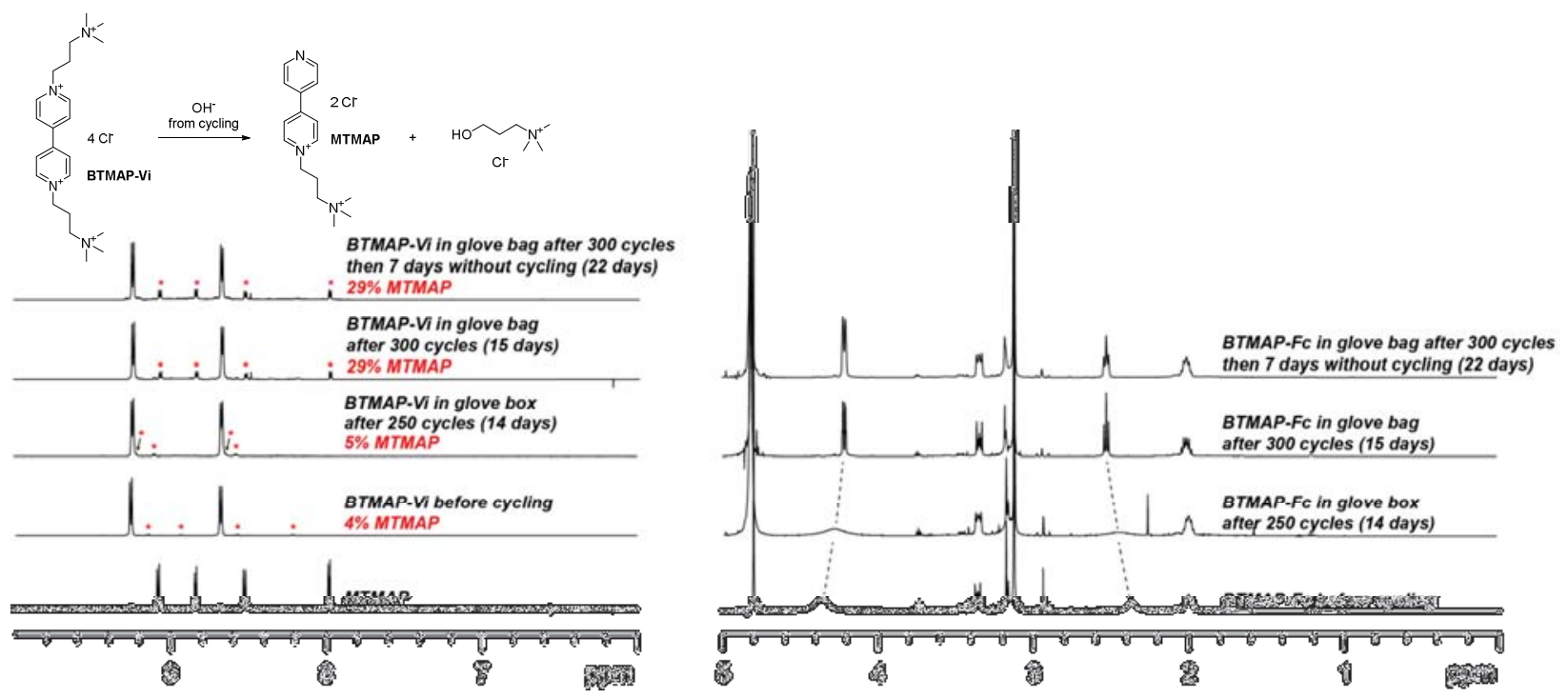

Figure S10. Evaluation of the chemical stability of BTMAP-Vi (left spectra) and BTMAP-Fc (right spectra) in both their oxidized and reduced forms. The presence of a small amount of paramagnetic impurity in some BTMAP-Fc samples results in the broadening of some peaks in its NMR spectrum. 
General information for synthesis. ${ }^{1} \mathrm{H}$ NMR and ${ }^{13} \mathrm{C}$ NMR spectra were recorded on Varian INOVA 500 spectrometers. NMR spectra were recorded in solutions of deuterated chloroform $\left(\mathrm{CDCl}_{3}\right)$ with the residual chloroform (7.24 ppm for ${ }^{1} \mathrm{H}$ NMR and $77.1 \mathrm{ppm}$ for $\left.{ }^{13} \mathrm{C} \mathrm{NMR}\right)$ taken as the internal standard, deuterated dimethyl sulfoxide $\left(\mathrm{DMSO}-\mathrm{d}_{6}\right)$ with the residual dimethyl sulfoxide (2.49 ppm for ${ }^{1} \mathrm{H}$ NMR and $39.5 \mathrm{ppm}$ for ${ }^{13} \mathrm{C}$ NMR) taken as the internal standard, or deuterium oxide $\left(\mathrm{D}_{2} \mathrm{O}\right)$ with deuterium hydroxide $\left(4.80 \mathrm{ppm}\right.$ for ${ }^{1} \mathrm{H}$ NMR) taken as the internal standard, and were reported in parts per million (ppm). Abbreviations for signal coupling are as follows: s, singlet; bs, broad singlet; d, doublet; t, triplet; q, quartet; dd, doublet of doublet; ddd, doublet of doublet of doublet; dt, doublet of triplet; $\mathrm{m}$, multiplet.

All reactions utilizing anhydrous solvents were carried out in flame-dried glassware under an argon atmosphere. When employed, anhydrous solvents were passed through columns of activated alumina immediately before use. All other solvents and reagents were purchased from Sigma-Aldrich, Alfa Aesar, or Oakwood Chemical, and were used as received unless otherwise specified. 


\section{Synthesis of BTMAP-Vi}

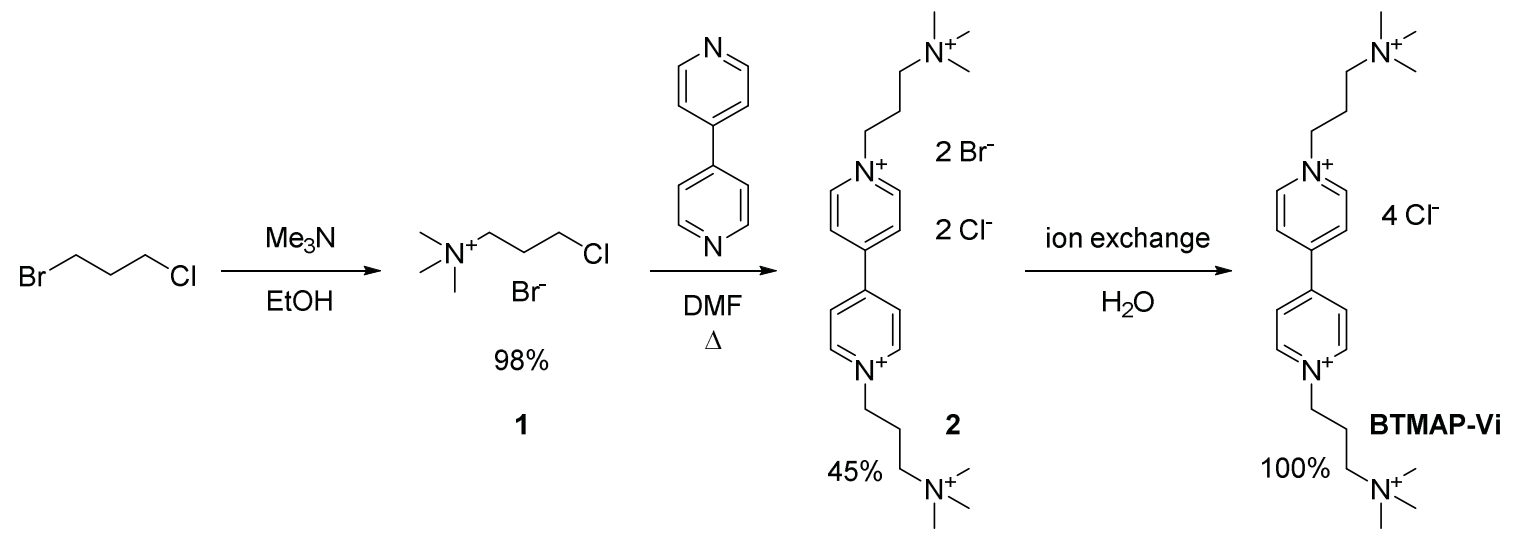

$99.19 \mathrm{~g}(630.0 \mathrm{mmol})$ of 1-bromo-3-chloropropane was stirred with $50.0 \mathrm{~mL}(210.0 \mathrm{mmol})$ of a 4.2 M solution of trimethylamine in ethanol. After stirring at room temperature for 15 hours, the reaction mixture was diluted with $\sim 500 \mathrm{~mL}$ of methyl tert-butyl ether (MTBE) and the suspended solid collected by vacuum filtration. The solid was rinsed with MTBE and dried in vacuo to give trimethyl(3-chloropropyl)ammonium bromide (1). Yield: $44.75 \mathrm{~g}(98.4 \%)$ of a fine white powder. This material was used without purification in the following step.

$44.75 \mathrm{~g}$ of 1 and $15.6180 \mathrm{~g}(100.0 \mathrm{mmol})$ of $4,4^{\prime}$-dipyridyl were suspended in $\sim 100 \mathrm{~mL}$ of anhydrous DMF and heated to reflux under argon. Upon heating, all solids dissolved, followed shortly after by the formation of a large amount of pale yellow precipitate. After heating for 1 hour, the reaction mixture had partially solidified and had turned greenish. The reaction was cooled to room temperature, whereupon $\sim 500 \mathrm{~mL}$ of isopropanol was added and the solid material was triturated until no trace of green coloration remained. The solid was collected by vacuum filtration, rinsed with isopropanol, then acetone, then finally dried in vacuo to give (3trimethylammonio)propyl viologen dibromide dichloride (2). Yield: $26.2701 \mathrm{~g}(44.6 \%)$ of a pale yellow powder.

A solution of $11.48 \mathrm{~g}(19.48 \mathrm{mmol})$ of 2 in $\sim 100 \mathrm{~mL}$ of deionized $\mathrm{H}_{2} \mathrm{O}$ was passed through $\sim 0.5 \mathrm{~kg}$ of wet Amberlite IRA-900 resin (chloride form). The resin was washed with $\sim 1 \mathrm{~L}$ of deionized $\mathrm{H}_{2} \mathrm{O}$ until the eluted solution produced no precipitate upon testing with aqueous $\mathrm{AgNO}_{3}$. The eluted solution was evaporated in vacuo to give pure (3-trimethylammonio)propyl viologen tetrachloride (BTMAP-Vi). Yield: $9.76 \mathrm{~g}(99.9 \%)$ of an off-white deliquescent solid.

${ }^{1}$ H NMR $\left(500 \mathrm{MHz}, \mathrm{D}_{2} \mathrm{O}\right) \delta 9.12(\mathrm{~d}, 4 \mathrm{H}), 8.63(\mathrm{~d}, 4 \mathrm{H}), 4.87(\mathrm{t}, 4 \mathrm{H}), 3.61(\mathrm{~m}, 4 \mathrm{H}), 3.22(\mathrm{~s}, 18 \mathrm{H})$, $2.72(\mathrm{~m}, 4 \mathrm{H}) .{ }^{13} \mathbf{C}$ NMR $\left(125 \mathrm{MHz}, \mathrm{D}_{2} \mathrm{O}\right) \delta 150.6,145.7,127.5,62.4,58.2,53.2,24.6$. 


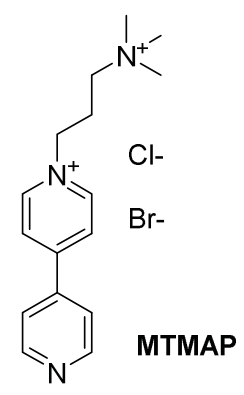

Note: If anhydrous $\mathrm{MeCN}$ is used instead of anhydrous DMF and the reaction worked up as specified, 1-(3-(trimethylammonio)propyl)-[4,4'-bipyridin]-1-ium bromide chloride (MTMAP) is obtained as the only product. As the main degradation product of BTMAP-Vi, its ${ }^{1} \mathrm{H}$ NMR spectrum was obtained for later studies on the chemical stability of BTMAP-Vi. ${ }^{1} \mathbf{H}$ NMR $\left(500 \mathrm{MHz}, \mathrm{D}_{2} \mathrm{O}\right) \delta 9.06(\mathrm{~d}, 2 \mathrm{H}), 8.82(\mathrm{~d}, 2 \mathrm{H}), 8.50(\mathrm{~d}, 2 \mathrm{H}), 7.97(\mathrm{~d}, 2 \mathrm{H}), 4.82(\mathrm{t}, 2 \mathrm{H}), 3.59(\mathrm{~m}$, $2 \mathrm{H}), 3.22(\mathrm{~s}, 9 \mathrm{H}), 2.68(\mathrm{~m}, 2 \mathrm{H})$. 


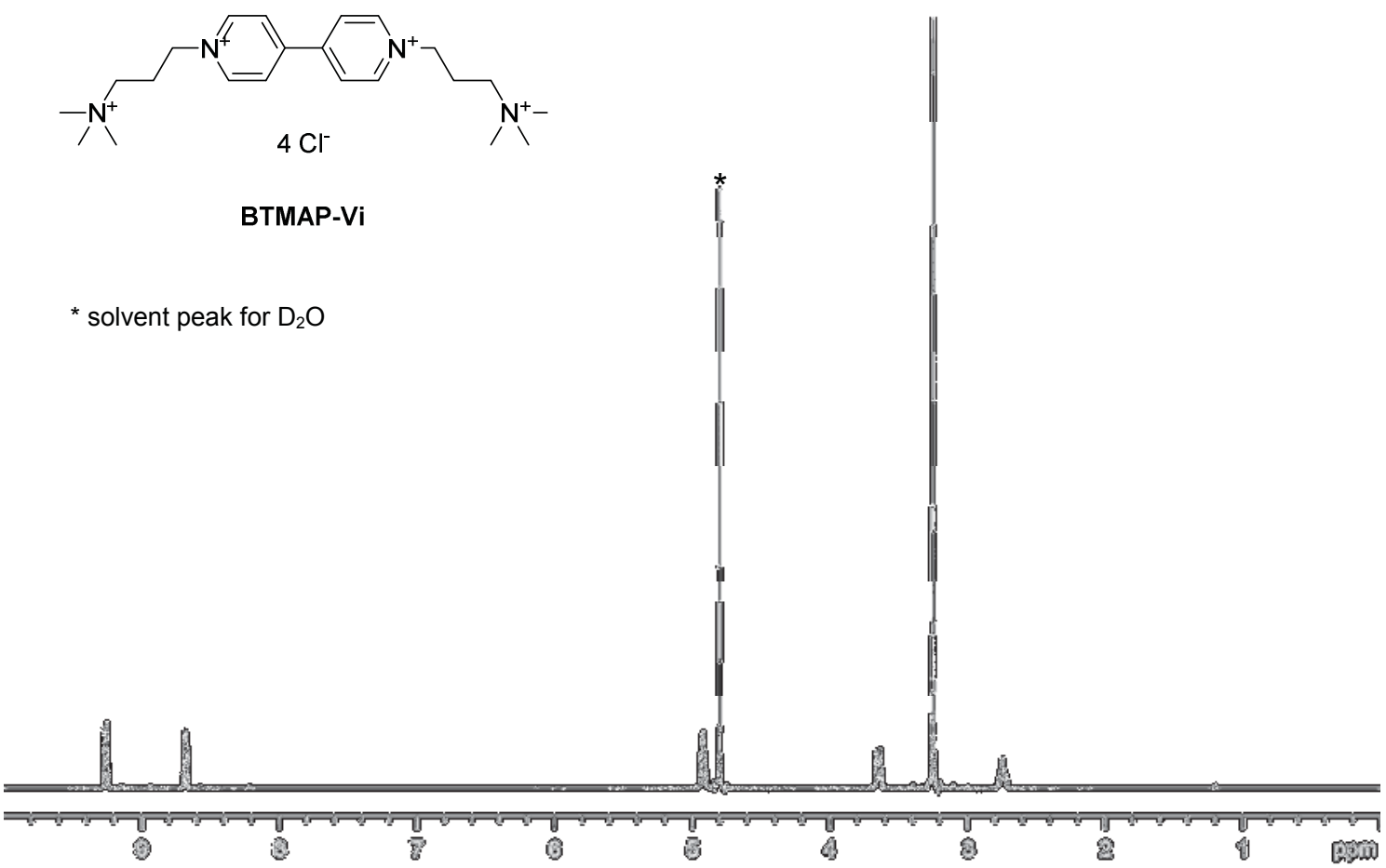

Figure S11. ${ }^{1} \mathrm{H}$ NMR spectrum of BTMAP-Vi, recorded in $\mathrm{D}_{2} \mathrm{O}$.

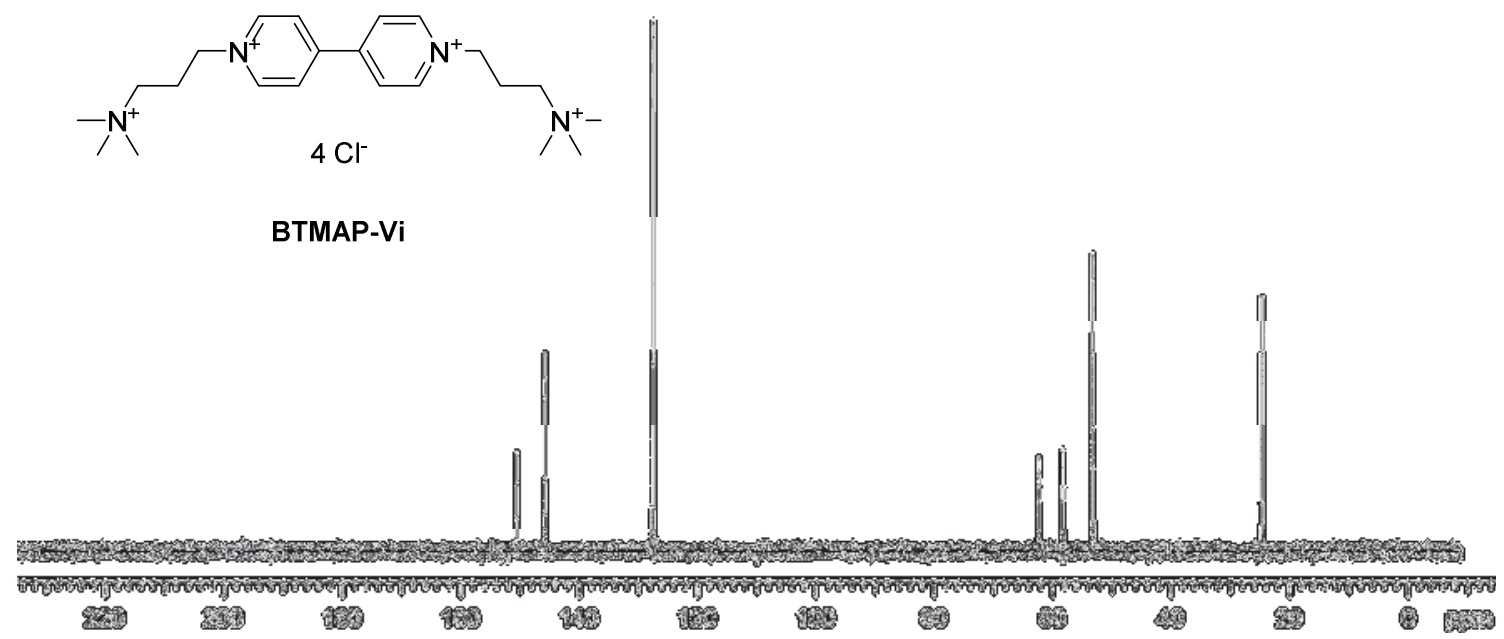

Figure S12. ${ }^{13} \mathrm{C}$ NMR spectrum of BTMAP-Vi, recorded in $\mathrm{D}_{2} \mathrm{O}$. 


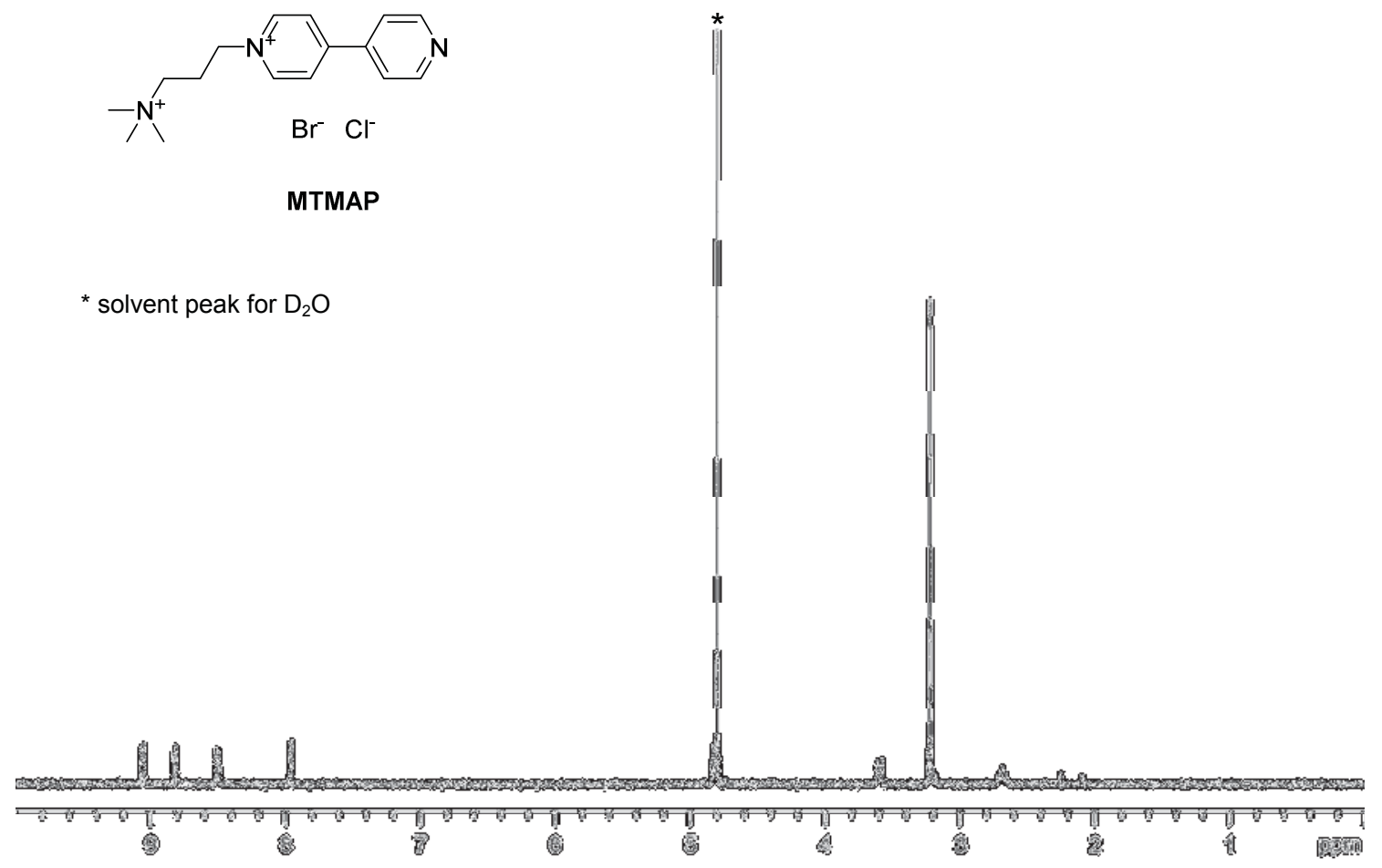

Figure S13. ${ }^{1} \mathrm{H}$ NMR spectrum of MTMAP, recorded in $\mathrm{D}_{2} \mathrm{O}$. 


\section{Synthesis of BTMAP-Fc}

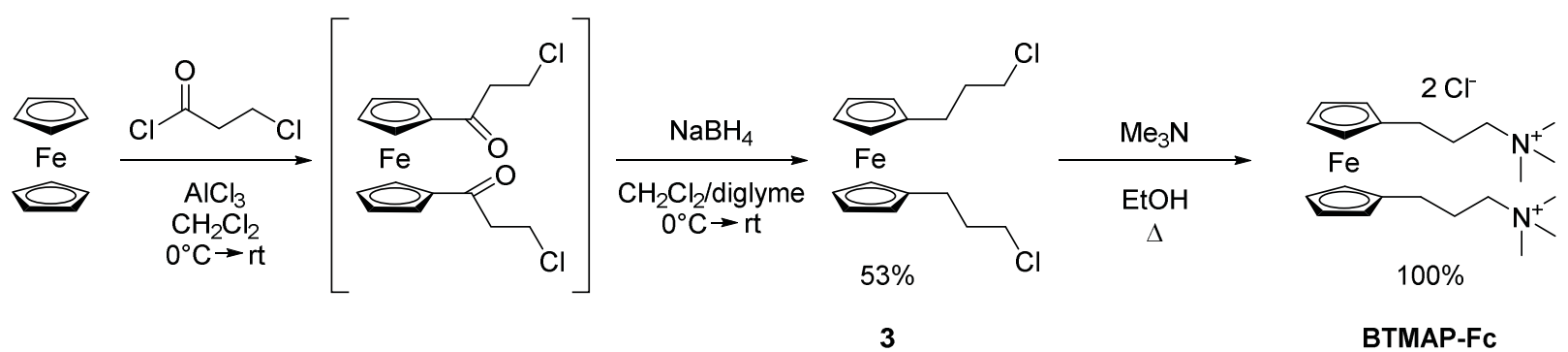

$14.67 \mathrm{~g}(110.0 \mathrm{mmol})$ of $\mathrm{AlCl}_{3}$ was suspended in $\sim 100 \mathrm{~mL}$ of anhydrous $\mathrm{CH}_{2} \mathrm{Cl}_{2}$. A solution of $12.70 \mathrm{~g}(100.0 \mathrm{mmol})$ of 3-chloropropionyl chloride in $\sim 50 \mathrm{~mL}$ of anhydrous $\mathrm{CH}_{2} \mathrm{Cl}_{2}$ was added by syringe and the mixture stirred at room temperature for 2 hours. Once this was complete, the resulting slightly turbid golden-yellow solution was transferred via cannula into another flask, which had been cooled to $0^{\circ} \mathrm{C}$, containing a solution of $9.30 \mathrm{~g}(50.0 \mathrm{mmol})$ of ferrocene in $\sim 100 \mathrm{~mL}$ of anhydrous $\mathrm{CH}_{2} \mathrm{Cl}_{2}$. After stirring overnight, the reaction mixture was again cooled to $0{ }^{\circ} \mathrm{C}$ and a solution of $200 \mathrm{~mL}$ of $0.5 \mathrm{M} \mathrm{NaBH}_{4}(100.0 \mathrm{mmol})$ in anhydrous diglyme was added via cannula and stirring was continued for a further 4 hours. Following that, the reaction was carefully quenched by the addition of $\sim 500 \mathrm{~mL}$ of $1 \mathrm{M}$ aqueous $\mathrm{HCl}$. The organic phase was isolated and the aqueous phase extracted with $\mathrm{CH}_{2} \mathrm{Cl}_{2}(3 \times 100 \mathrm{~mL})$. The extracts were combined, dried over anhydrous $\mathrm{Na}_{2} \mathrm{SO}_{4}$, filtered and evaporated to give the crude product of 1,1'-bis(3-chloropropyl)ferrocene (3). Yield: $16.02 \mathrm{~g}(94.5 \%)$ of a red-brown oil.

${ }^{1}$ H NMR (500 MHz, DMSO-d 6 ) $\delta 4.01(\mathrm{~m}, 8 \mathrm{H}), 3.62(\mathrm{t}, 4 \mathrm{H}), 2.41(\mathrm{~m}, 4 \mathrm{H}), 1.90(\mathrm{~m}, 4 \mathrm{H}) ;{ }^{13} \mathbf{C}$ NMR $\left(125 \mathrm{MHz}, \mathrm{DMSO}-\mathrm{d}_{6}\right) \delta 87.3,68.3,67.7,45.1,33.3,25.9$.

$16.02 \mathrm{~g}$ (47.3 mmol) of crude 3 was dissolved in $\sim 100 \mathrm{~mL}$ of a 4.2 M solution of trimethylamine in ethanol. The solution was sealed in a heavy-walled glass tube and heated to $60{ }^{\circ} \mathrm{C}$ for 5 days. Following that, all volatiles were removed in vacuo to give a dark brown oil. The oil was stirred in $\mathrm{H}_{2} \mathrm{O}(\sim 400 \mathrm{~mL})$ and filtered to remove unreacted ferrocene and other water-insoluble impurities. The filtrate was evaporated in vacuo to give pure BTMAP-Fc. Yield: $20.76 \mathrm{~g}$ (96.1\%) of a dark brown glassy solid. If this step is performed with column-purified 1,1'-bis(3chloropropyl)ferrocene, no further purification is required after evaporating all the solvent. If starting from purified 3, BTMAP-Fc is obtained as an orange-yellow powder.

${ }^{1} \mathbf{H}$ NMR $\left(500 \mathrm{MHz}, \mathrm{D}_{2} \mathrm{O}\right) \delta 4.15(\mathrm{~m}, 8 \mathrm{H}), 3.27(\mathrm{~m}, 4 \mathrm{H}), 3.05(\mathrm{~s}, 18 \mathrm{H}), 2.55(\mathrm{t}, 4 \mathrm{H}), 1.94(\mathrm{~m}$, $4 \mathrm{H}) ;{ }^{13} \mathrm{C}$ NMR $\left(125 \mathrm{MHz}, \mathrm{D}_{2} \mathrm{O}\right) \delta 87.1,69.0,68.4,66.1,52.7,25.2,24.0$. 


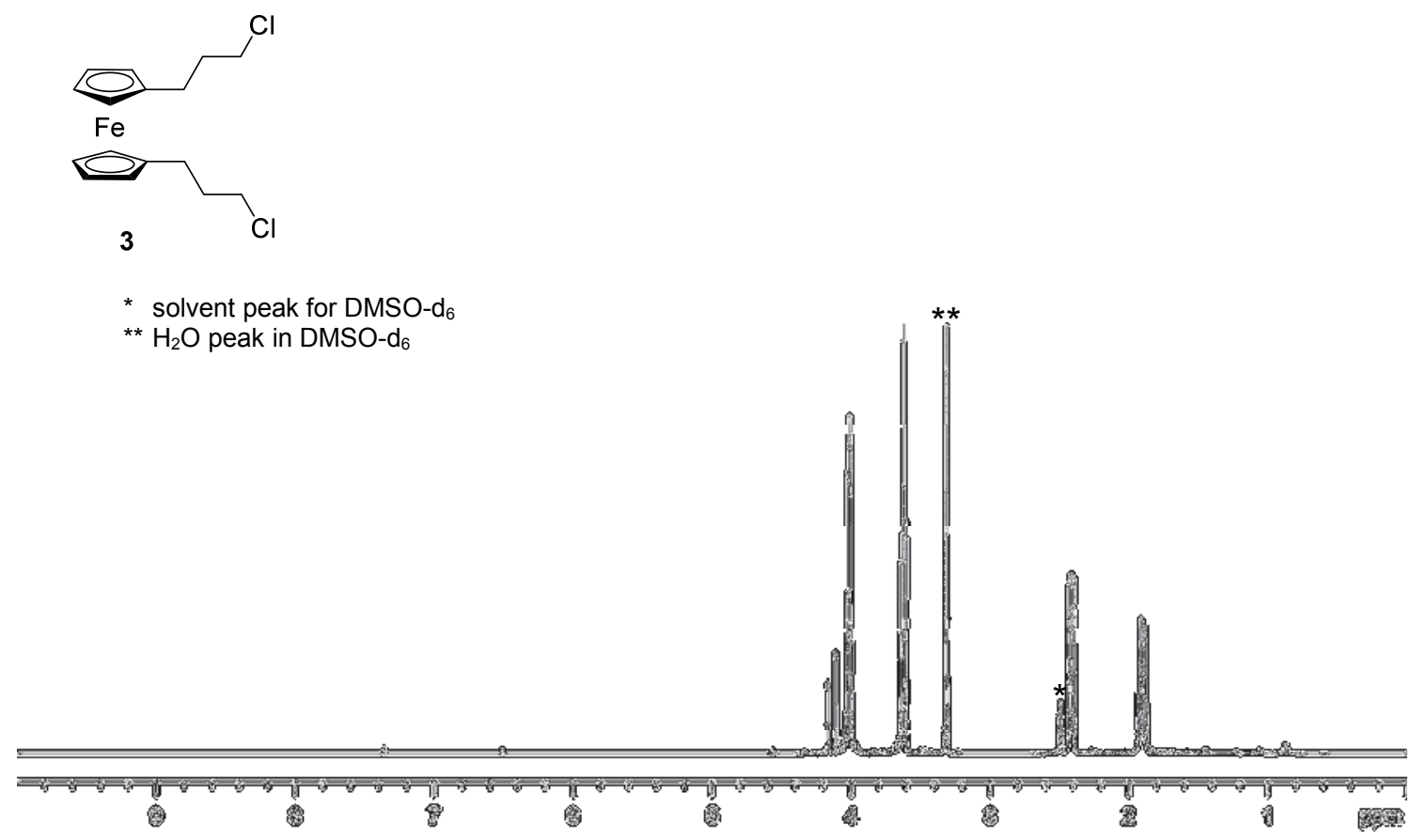

Figure S14. ${ }^{1} \mathrm{H}$ NMR spectrum of $\mathbf{3}$, recorded in DMSO-d $\mathrm{d}_{6}$.

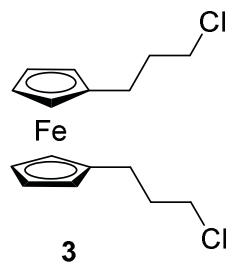

* solvent peak for DMSO-d $d_{6}$

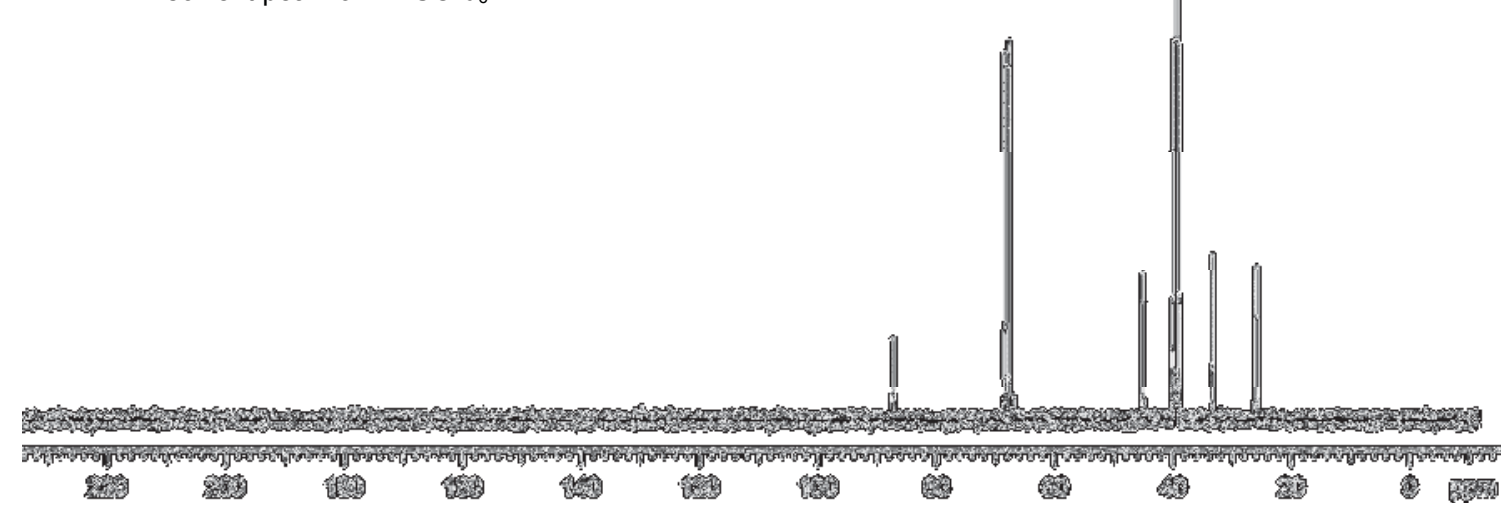

Figure S15. ${ }^{13} \mathrm{C}$ NMR spectrum of $\mathbf{3}$, recorded in DMSO- $\mathrm{d}_{6}$. 


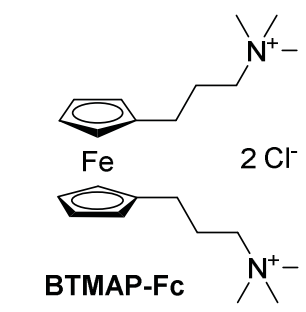

* solvent peak for $D_{2} \mathrm{O}$

Figure S16. ${ }^{1} \mathrm{H}$ NMR spectrum of BTMAP-Fe, recorded in $\mathrm{D}_{2} \mathrm{O}$.

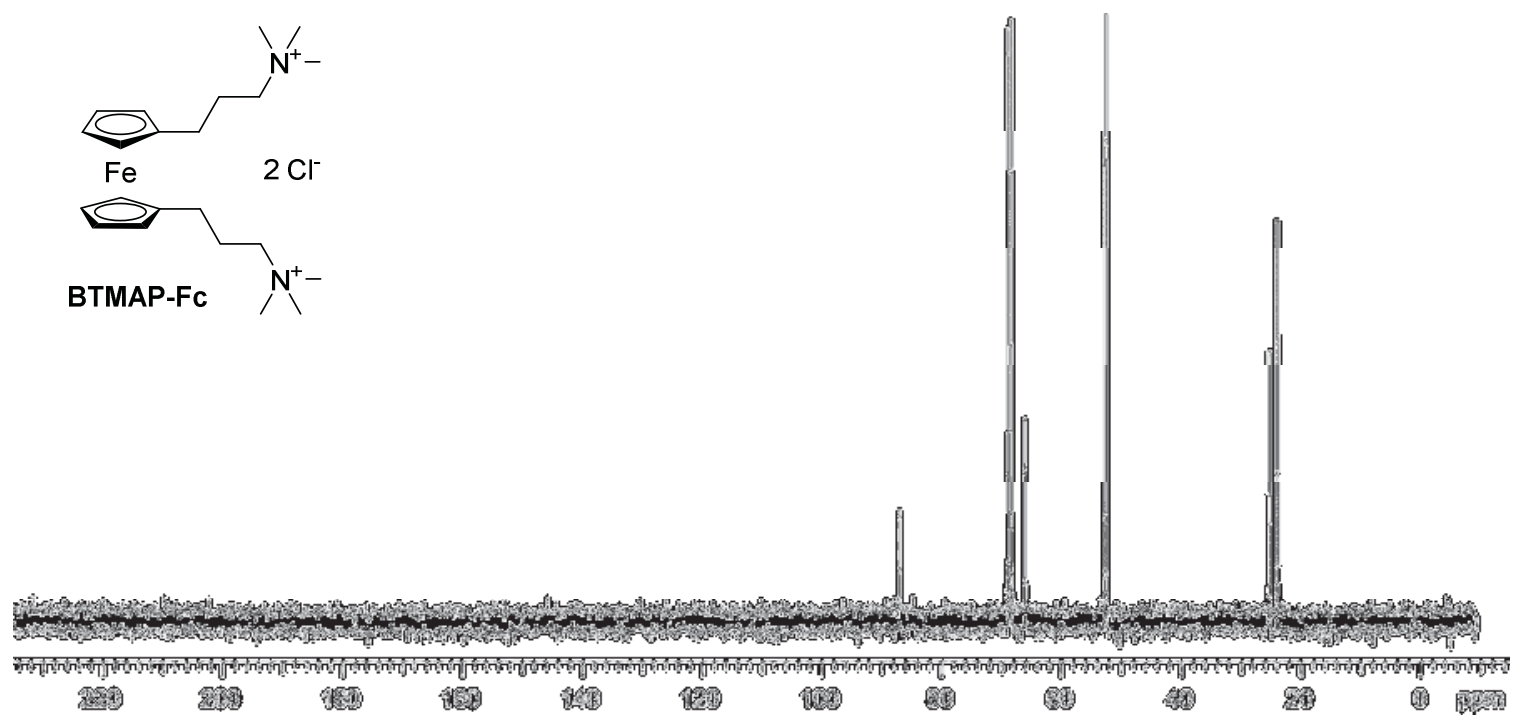

Figure S17. ${ }^{13} \mathrm{C}$ NMR spectrum of BTMAP-Fe, recorded in $\mathrm{D}_{2} \mathrm{O}$. 


\section{Synthesis of FcCONH-TMAP}

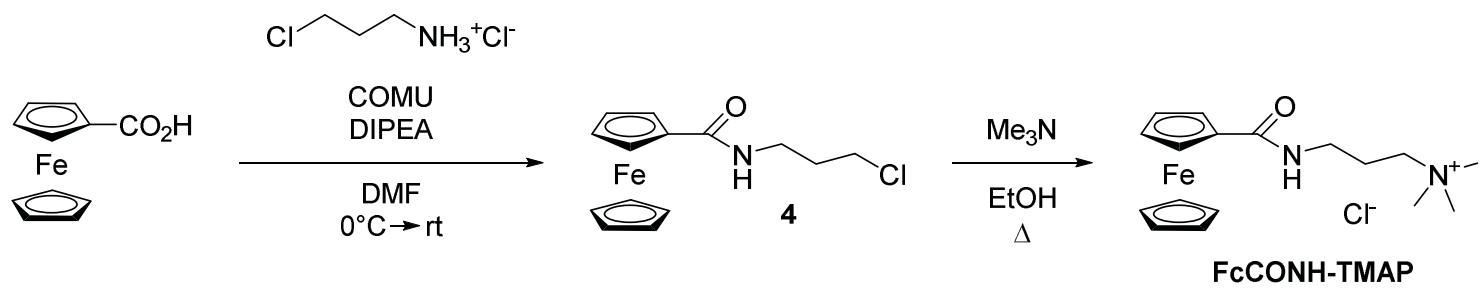

$230.0 \mathrm{mg} \quad(1.00 \mathrm{mmol}) \quad$ of ferrocenecarboxylic acid, $156.0 \mathrm{mg} \quad(1.20 \mathrm{mmol})$ of 3chloropropylamine hydrochloride, $513.9 \mathrm{mg} \quad(1.20 \mathrm{mmol}) \quad$ of (1-cyano-2-ethoxy-2oxoethylidenaminooxy)dimethylaminomorpholinocarbenium hexafluorophosphate (COMU), and $323.1 \mathrm{mg}$ ( $2.50 \mathrm{mmol})$ of DIPEA were stirred in $10 \mathrm{~mL}$ of DMF. After 2 hours, the reaction was diluted with $50 \mathrm{~mL}$ of EtOAc, then washed successively with $1 \mathrm{M} \mathrm{NaOH}(3 \times 50 \mathrm{~mL}), 1 \mathrm{M} \mathrm{HCl}$ $(3 \times 50 \mathrm{~mL})$, water $(1 \times 50 \mathrm{~mL}), 5 \%$ aqueous $\mathrm{Na}_{2} \mathrm{~S}_{2} \mathrm{O}_{4}(1 \times 100 \mathrm{~mL})$, then finally $5 \%$ aqueous $\mathrm{LiCl}(1 \times 100 \mathrm{~mL})$. The organic phase was dried over anhydrous $\mathrm{Na}_{2} \mathrm{SO}_{4}$, filtered, and evaporated to give pure 4. Yield: $300.4 \mathrm{mg}(98.3 \%)$ of an orange-yellow powder.

${ }^{1}$ H NMR (500 MHz, DMSO-d $\left.{ }_{6}\right) \delta 7.85(\mathrm{t}, 1 \mathrm{H}), 4.77(\mathrm{t}, 2 \mathrm{H}), 4.33(\mathrm{t}, 2 \mathrm{H}), 4.14(\mathrm{~s}, 5 \mathrm{H}), 3.69(\mathrm{t}$, 2H), 3.28 (q, 2H), $1.95(\mathrm{~m}, 2 \mathrm{H}) ;{ }^{13} \mathbf{C}$ NMR (125 MHz, DMSO-d 6 ) $\delta 168.9,76.5,69.7,69.1$, $68.0,43.0,36.1,32.4$.

$258.9 \mathrm{mg}$ of 4 produced in the previous step was stirred with $25 \mathrm{~mL}$ of a $4.2 \mathrm{M}$ solution of trimethylamine in ethanol. The solution was sealed in a heavy-walled glass tube and heated to $60{ }^{\circ} \mathrm{C}$ for 5 days. Following that, all volatiles were removed in vacuo to give FcCONH-TMAP. Yield: $288.9 \mathrm{mg}(93.5 \%)$ of a dark brown foam.

${ }^{1} \mathbf{H}$ NMR $\left(500 \mathrm{MHz}, \mathrm{CDCl}_{3}\right) \delta 7.93(\mathrm{t}, 1 \mathrm{H}), 4.77(\mathrm{t}, 2 \mathrm{H}), 4.35(\mathrm{t}, 2 \mathrm{H}), 4.17(\mathrm{~s}, 5 \mathrm{H}), 3.24(\mathrm{~m}, 4 \mathrm{H})$, 3.06 (s, 9H), $1.91(\mathrm{~m}, 2 \mathrm{H}) ;{ }^{13} \mathrm{C}$ NMR $\left(125 \mathrm{MHz}, \mathrm{CDCl}_{3}\right) \delta 174.4,73.6,71.6,70.0,68.3,64.3$, 52.9 (3 separate peaks), 36.2, 23.0.

The cyclic voltammogram of FcCONH-TMAP is shown in Figure S4. 


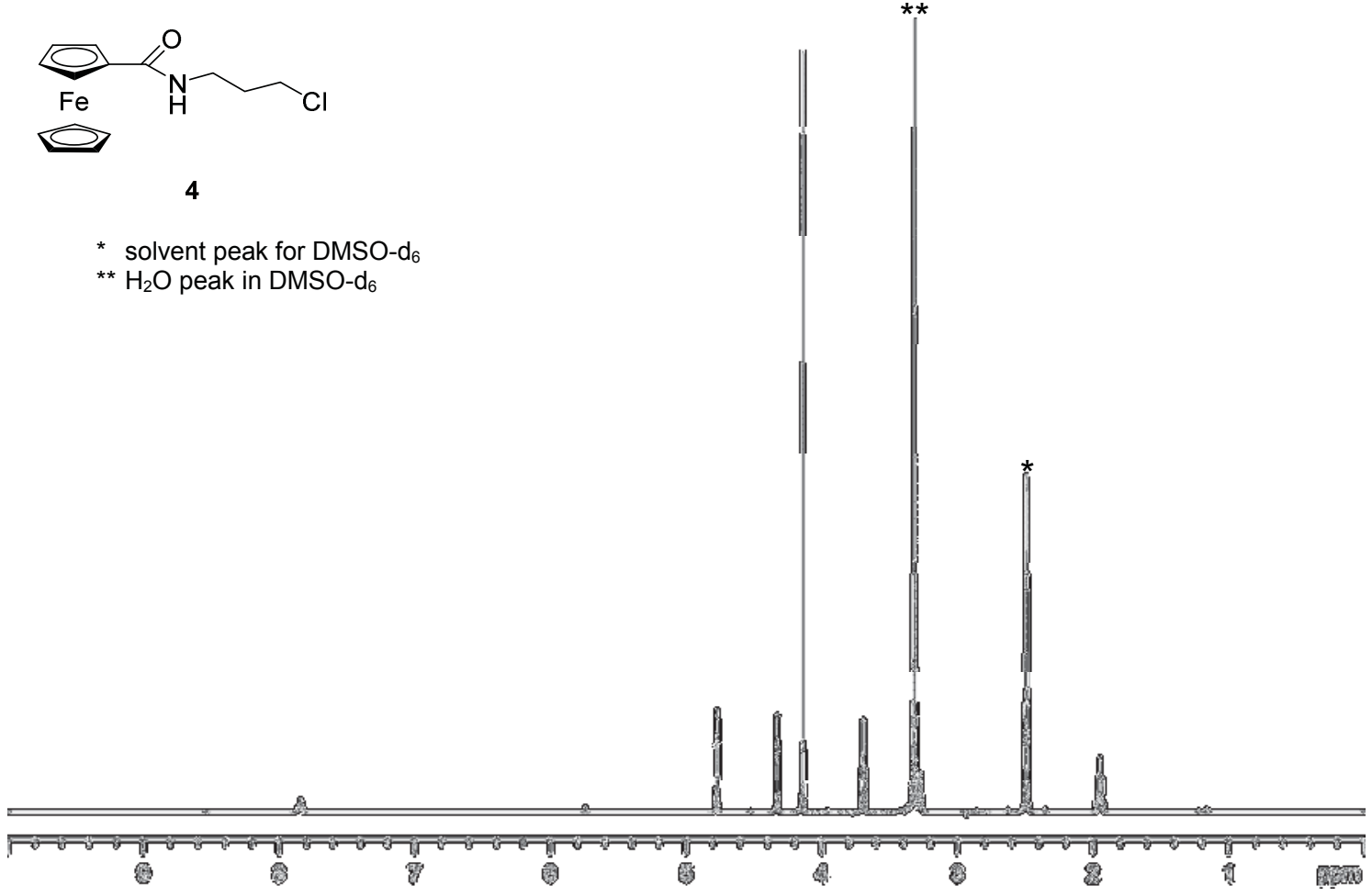

Figure S18. ${ }^{1} \mathrm{H}$ NMR spectrum of 4 , recorded in DMSO-d ${ }_{6}$.

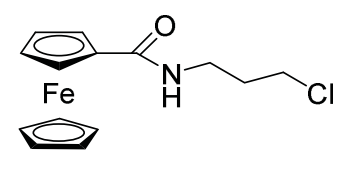

4

* solvent peak for DMSO-d

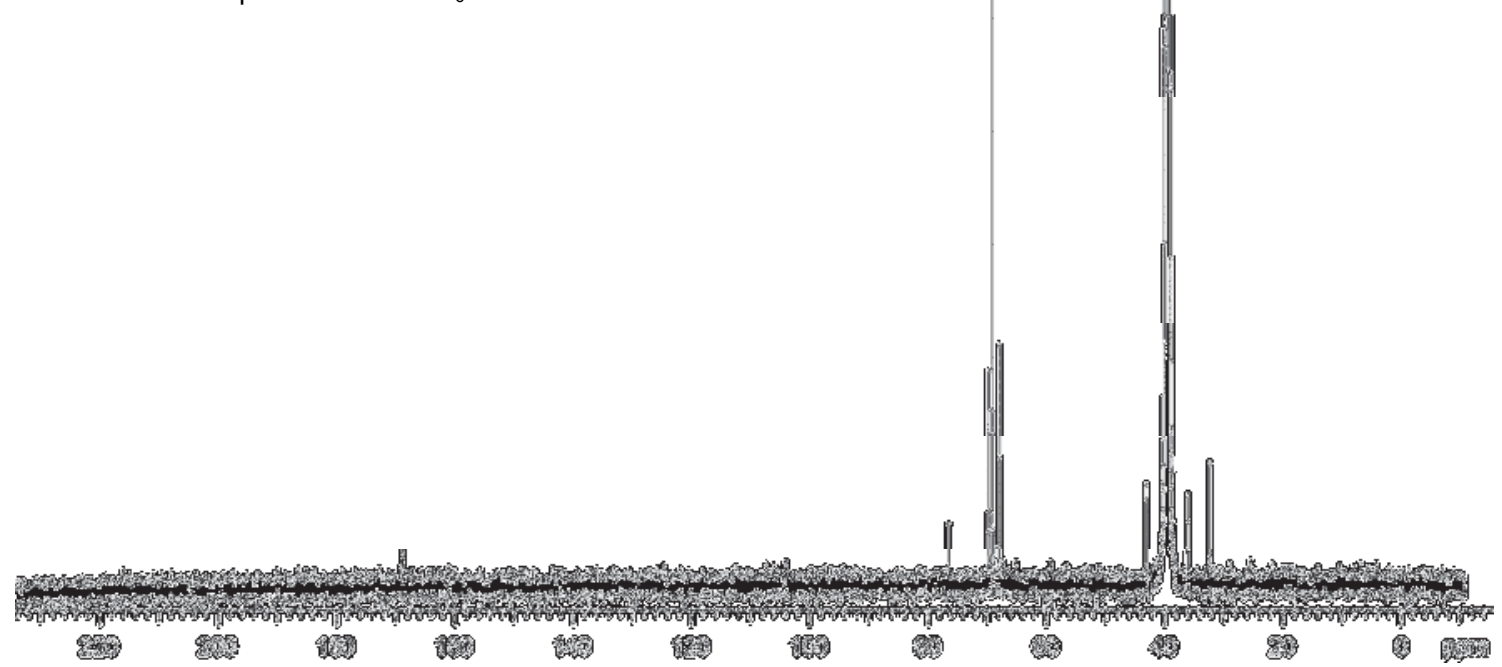

Figure S19. ${ }^{13} \mathrm{C}$ NMR spectrum of $\mathbf{4}$, recorded in DMSO-d $\mathrm{d}_{6}$. 


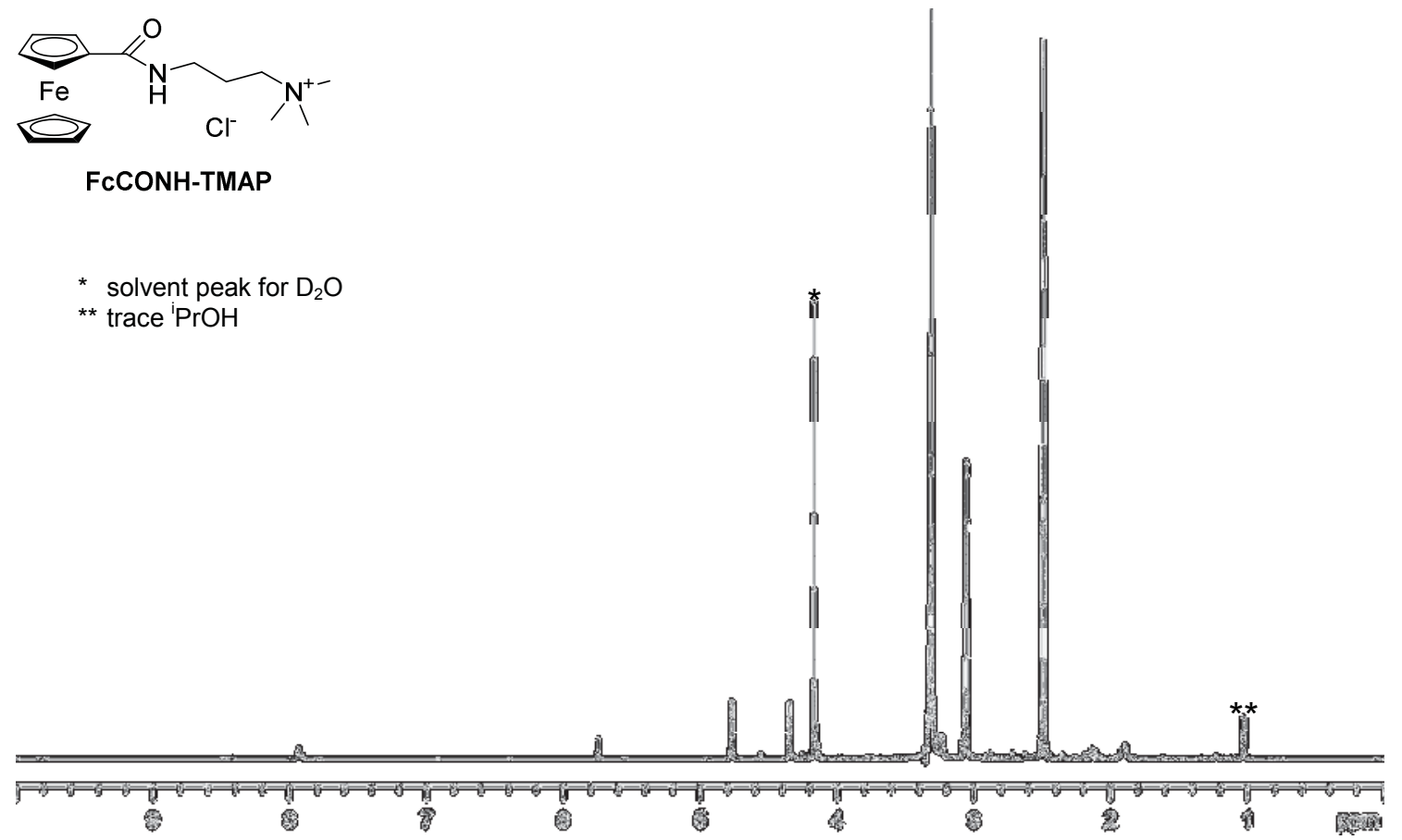

Figure S20. ${ }^{1} \mathrm{H}$ NMR spectrum of FcCONH-TMAP, recorded in $\mathrm{D}_{2} \mathrm{O}$.
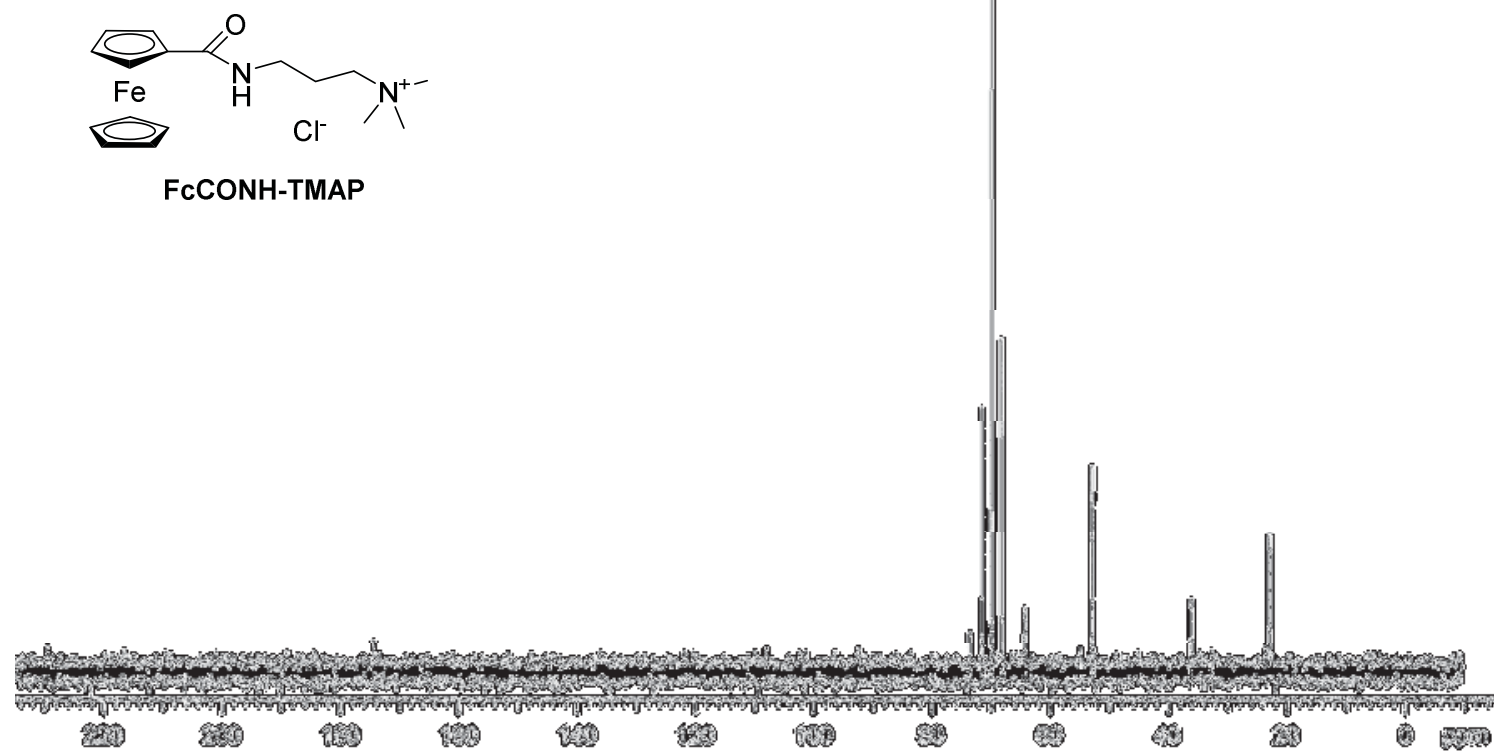

Figure S21. ${ }^{1} \mathrm{H}$ NMR spectrum of FcCONH-TMAP, recorded in $\mathrm{D}_{2} \mathrm{O}$. 


\section{References}

(1) Liu, T.; Wei, X.; Nie, Z.; Sprenkle, V.; Wang, W. A Total Organic Aqueous Redox Flow Battery Employing a Low Cost and Sustainable Methyl Viologen Anolyte and 4-HO-TEMPO Catholyte. Adv. Energy Mater. 2016, 6, 1501449.

(2) Janoschka, T.; Martin, N.; Martin, U.; Friebe, C.; Morgenstern, S.; Hiller, H.; Hager, M. D.; Schubert, U. S. An Aqueous, Polymer-Based Redox-Flow Battery Using Non-Corrosive, Safe, and Low-Cost Materials. Nature 2015, 527, 78-81.

(3) Janoschka, T.; Martin, N.; Hager, M. D.; Schubert, U. S. An Aqueous Redox-Flow Battery with High Capacity and Power: The TEMPTMA/MV System. Angew. Chem. Int. Ed. 2016, 55, 14427-14430.

(4) Hu, B.; Debruler, C.; Rhodes, Z.; Liu, T. A Long Cycling Aqueous Organic Redox Flow Battery (AORFB) Towards Sustainable and Safe Energy Storage. J. Am. Chem. Soc. 2017, 139, 1207-1214.

(5) Orita, A.; Verde, M. G.; Sakai, M.; Meng, Y. S. The Impact of pH on Side Reactions for Aqueous Redox Flow Batteries Based on Nitroxyl Radical Compounds. J. Power Sources 2016, 321, 126-134.

(6) Bird, C. L.; Kuhn, A. T. Electrochemistry of the Viologens. Chem. Soc. Rev. 1981, 10, 49-82.

(7) Rieger, A. L.; Edwards, J. O. Methyl Viologen Reactions. 5. Rates and Mechanism of Cation-Radical Formation in Aqueous Base. J. Org. Chem. 1988, 53, 1481-1485.

(8) Kosower, E. M.; Cotter, J. L. Stable Free Radicals. II. The Reduction of 1-Methyl-4Cyanopyridinium Ion to Methylviologen Cation Radical. J. Am. Chem. Soc. 1964, 86, 55245527.

(9) Zhang, D.-W.; Tian, J.; Chen, L.; Zhang, L.; Li, Z.-T. Dimerization of Conjugated Radical Cations: An Emerging Non-Covalent Interaction for Self-Assembly. Chem. Asian J. 2015, 10, 56-68.

(10) Bard, A. J.; Ledwith, A.; Shine, H. J. Formation, Properties and Reactions of Cation Radicals in Solution. Adv. Phys. Org, Chem. 1976, 13, 155-278.

(11) Venturi, M.; Mulazzani, Q. G.; Hoffman, M. Z. Radiolytically-Induced One-Electron Reduction of Methyl Viologen in Aqueous Solution. Rad. Phys. Chem. (1977) 1984, 23, 229236.

(12) Hurvois, J. P.; Moinet, C. Reactivity of Ferrocenium Cations with Molecular Oxygen in Polar Organic Solvents: Decomposition, Redox Reactions and Stabilization. J. Organomet. Chem. 2005, 690, 1829-1839.

(13) Connelly, N. G.; Geiger, W. E. Chemical Redox Agents for Organometallic Chemistry. Chem. Rev. 1996, 96, 877-910.

(14) Tabbì, G.; Cassino, C.; Cavigiolio, G.; Colangelo, D.; Ghiglia, A.; Viano, I.; Osella, D. Water Stability and Cytotoxic Activity Relationship of a Series of Ferrocenium Derivatives. ESR Insights on the Radical Production During the Degradation Process. J. Med. Chem. 2002, 45, 5786-5796.

(15) Thomas, J.-L.; Howarth, J.; Hanlon, K.; McGuirk, D. Ferrocenyl Imidazolium Salts as a New Class of Anion Receptors with $\mathrm{C}-\mathrm{H} \cdots \mathrm{X}^{-}$Hydrogen Bonding. Tet. Lett. 2000, 41, 413-416.

(16) Gasser, G.; Fischmann, A. J.; Forsyth, C. M.; Spiccia, L. Products of Hydrolysis of (Ferrocenylmethyl)trimethylammonium Iodide: Synthesis of Hydroxymethylferrocene and Bis(ferrocenylmethyl) Ether. J. Organomet. Chem. 2007, 692, 3835-3840. 
(17) Lin, K.; Gómez-Bombarelli, R.; Beh, E. S.; Tong, L.; Chen, Q.; Valle, A.; Aspuru-Guzik, A.; Aziz, M. J.; Gordon, R. G. A Redox-Flow Battery with an Alloxazine-Based Organic Electrolyte. Nat. Energy 2016, 1, 16102.

(18) Xie, W.; Cook, J.; Park, H. B.; Freeman, B. D.; Lee, C. H.; McGrath, J. E. Fundamental Salt and Water Transport Properties in Directly Copolymerized Disulfonated Poly(Arylene Ether Sulfone) Random Copolymers. Polymer 2011, 52, 2032-2043. 